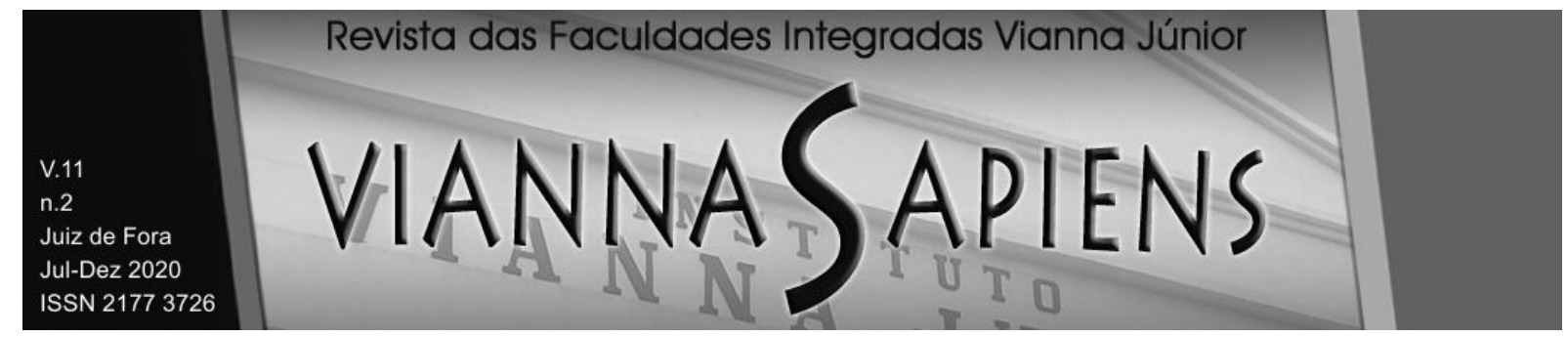

\title{
Análise de viabilidade econômico-financeira de franquia de artigos de presentes e decoração
}

DOI: 10.31994/rvs.v11i2.658

Laysa Rachid Gomes ${ }^{1}$

Tatielle Menolli Longhini

\section{RESUMO}

O empreendedorismo, ao fomentar novos negócios ou mudar outros já existentes, gera renda e alternativas econômicas. Investir é arriscado, sendo o estudo de viabilidade fundamental para redução de cenários de incertezas. Este trabalho visa analisar a viabilidade econômico-financeira de uma franquia de artigos de presentes e decoração, em um shopping de Vitória da Conquista-BA, através de pesquisa de mercado e de ferramentas financeiras, tais como Demonstração de Fluxo de Caixa (DFC), Retorno sobre o Capital Investido (ROIC), valor presente líquido (VPL), a taxa interna de retorno (TIR) e payback. Para isso, foram levantados dados e projeções da franqueadora e do município de instalação. Projetou-se payback de 35 meses, TIR de $1,88 \%$ ao mês, VPL de $\mathrm{R} \$ 82.731,00$ e indicação do ROIC de crescimento ao longo dos anos. Um cenário satisfatório ao empreendedor, dados os bons indicadores econômicos da cidade e as oportunidades no segmento de atuação.

\footnotetext{
${ }^{1}$ Graduada em Engenharia de Produção pelo Instituto Federal de Minas Gerais campus Governador Valadares (IFMG-GV), E-mail: laysarachid@gmail.com, ORCID ID 0000-0001-9316-7261.

${ }^{2}$ Mestre em Administração pela Universidade Federal de Minas Gerais (UFMG), Professora do curso de Engenharia de Produção pelo Instituto Federal de Minas Gerais campus Governador Valadares (IFMG-GV), E-mail: tatielle.longhini@ifmg.edu.br, ORCID ID 0000-0002-2934-9893.
} 


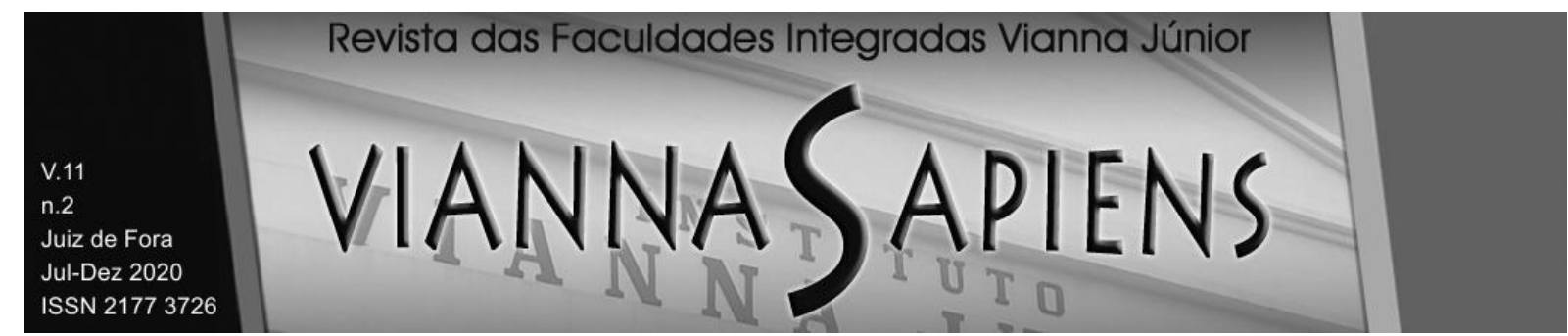

\title{
PALAVRAS-CHAVE: FRANQUIA. INVESTIMENTO. FLUXO DE CAIXA. RETORNO SOBRE O CAPITAL INVESTIDO.
}

\section{Economic and financial viability analysis of the franchise of gifts and decoration articles}

\begin{abstract}
Entrepreneurship, by promoting new businesses or changing existing ones, generates income and economic alternatives. Investing is risky, and it is a fundamental feasibility study for reducing uncertainty scenarios. This work aims to analyze the economic and financial viability of a franchise of gift and decoration items, in a mall in Vitória da Conquista-BA, through market research and financial tools, such as Cash Flow Statement (DFC), Return on Invested Capital (ROIC), net present value (NPV), internal rate of return (IRR) and payback. For this, data and projections of the franchisor and the municipality of installation were collected. A 35month payback was projected, an IRR of $1.88 \%$ per month, NPV of R $\$ 82,731.00$ and an indication of the growth ROIC over the years. A satisfactory scenario for entrepreneur, given the good economic indicators of the city and the opportunities in the segment in which it operates.
\end{abstract}

KEY WORDS: FRANCHISING. INVESTMENT. CASH FLOW. RETURN ON INVESTED CAPITAL. 


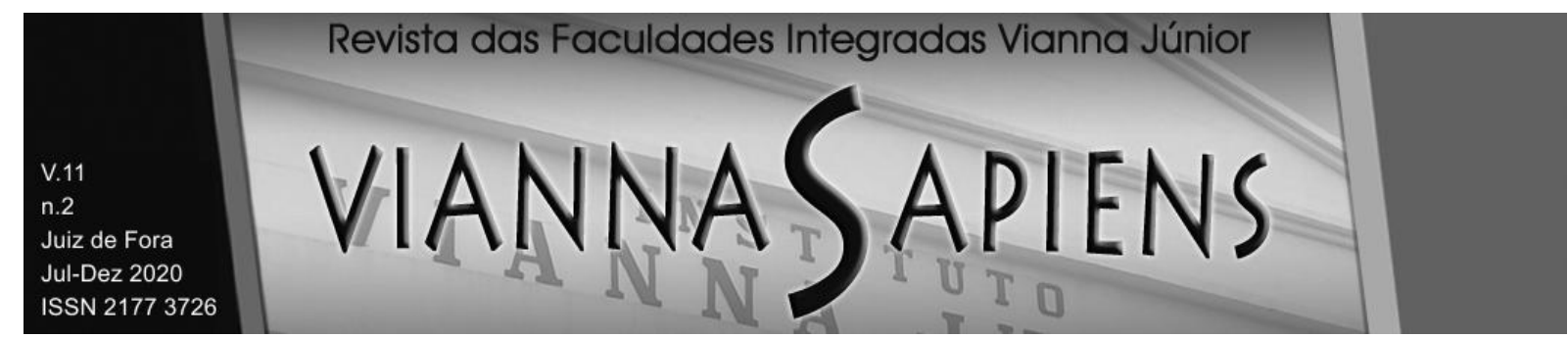

\section{INTRODUÇÃO}

O empreendedorismo é forte no Brasil e contribui para geração de empregos e de renda - principalmente entre os micros e pequenos negócios, em que o percentual de participação no PIB cresceu para 27\% em 2011 (ABF, 2018). No entanto, com a crise brasileira de 2015, o saldo de empresas foi negativo, tendo elevado a competitividade por sobrevivência. Isso despertou mudanças no mercado, sendo retomada tanto a expansão quanto o investimento (MASCARENHAS et al, 2015; ABF, 2018; BAKKER, SALGADO, 2016; IBGE, 2016).

Neste cenário, o setor de franquias vem ganhando força, dada a possibilidade de uso de uma marca já consolidada e de conhecimentos administrativos proporcionados pelo franqueador. Em 2018, houve crescimento de 7,06\% no faturamento relação ao ano anterior, o que equivale a 11,524 bilhões de reais totalizando $R \$ 174,843$ bilhões (ABF, 2018). A expectativa para os próximos anos também é de expansão, sendo esperado um aumento de 8 a $10 \%$ no faturamento e um acréscimo de 5 a $6 \%$ de unidades em todo o país.

No entanto, os riscos de investimento ainda existem. Para reduzir essas incertezas, o estudo de análise de viabilidade econômica pode favorecer a tomada de decisão quanto à aquisição de uma franquia (RIBEIRO et al, 2013).

Por isso, é comum o uso de ferramentas de demonstração contábil, tais como a Demonstração de Fluxo de Caixa (DFC) e o Retorno sobre o Capital Investido (ROIC). Com o DFC são extraídas informações financeiras quanto ao fluxo de caixa gerado e aos investimentos necessários (ROSS, 2000; SATO, 2007). Já o ROIC apresenta o desempenho operacional efetivo da organização, que reflete na sua capacidade em rentabilizar o investimento total (ASSAF NETO, 2012; COPELAND et al, 2002; TEIXEIRA, 2008; NEVES, 2011).

Adicionalmente, também é feita a análise econômico-financeira onde, através de fluxos de caixa e cálculos de taxas internas de retorno (TIR) e de tempo de retorno de investimento, são identificadas as melhores oportunidades de 


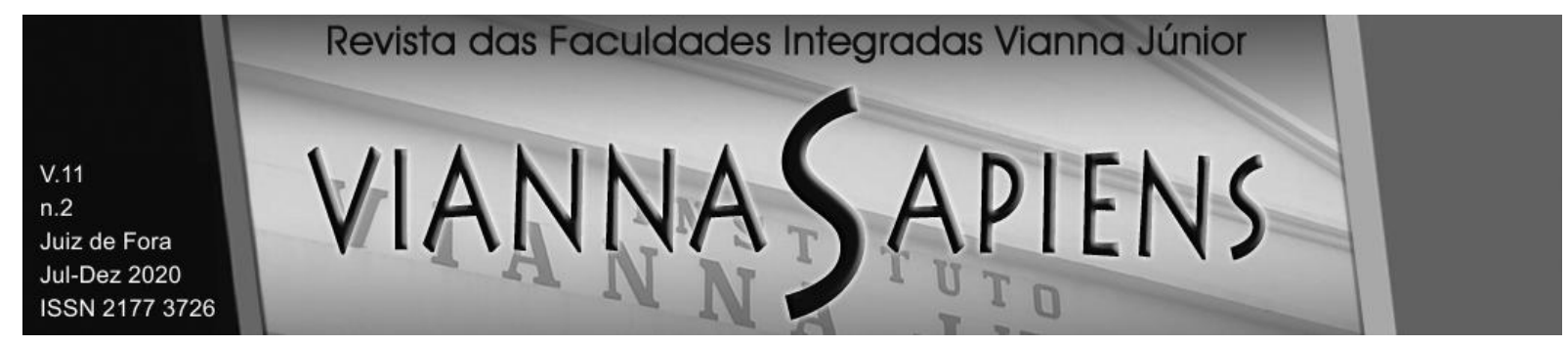

investimento, de modo que os resultados superem o valor investido (MOYEN; PLATIKANOV, 2012). Por fim, é comum o desenvolvimento de uma pesquisa de mercado, com levantamento sistemático de informações para identificar e resolver problemas através de avaliação criteriosa e objetiva (ZAMBERLAN, 2008; BOYD, WESTFALL; 1978; TEIXEIRA, 1997; LIZOTE et al, 2014).

Este trabalho foi realizado a partir do interesse de um empresário em abrir uma franquia, em shopping recém-lançado na cidade de Vitória da Conquista-BA. Dessa maneira, objetiva-se analisar a viabilidade econômico-financeira de uma franquia de artigos de presente e decoração, de modo a embasar a decisão de investimento.

Para isso, foram avaliados resultados de demonstrações contábeis, pelo ROIC e pelo DFC, de viabilidade econômico-financeira, por VPL, TIR e payback e de pesquisa de mercado através de dados e projeções da empresa franqueadora. A seguir, o estudo apresenta uma revisão bibliográfica dos principais assuntos abordados, a metodologia utilizada para o estudo, seguida dos resultados e discussões e da conclusão.

\section{REVISÃO BIBLIOGRÁFICA}

Esta seção contempla a abordagem de conceitos essenciais à análise de investimento, bem como relevantes informações sobre o mercado de franquias e alguns dos seus indicadores e, além disso, aborda a pesquisa de mercado.

\subsection{Mercado de franquias em shopping centers}

Segundo o Ibope Inteligência (2012), onze milhões de pessoas passam pelos shopping centers do país todos os dias e $79 \%$ dos consumidores são das classes $A$ e B; se acrescentar a classe $\mathrm{C} 1$, esse percentual chega a $93 \%$. O censo da Abrasce 


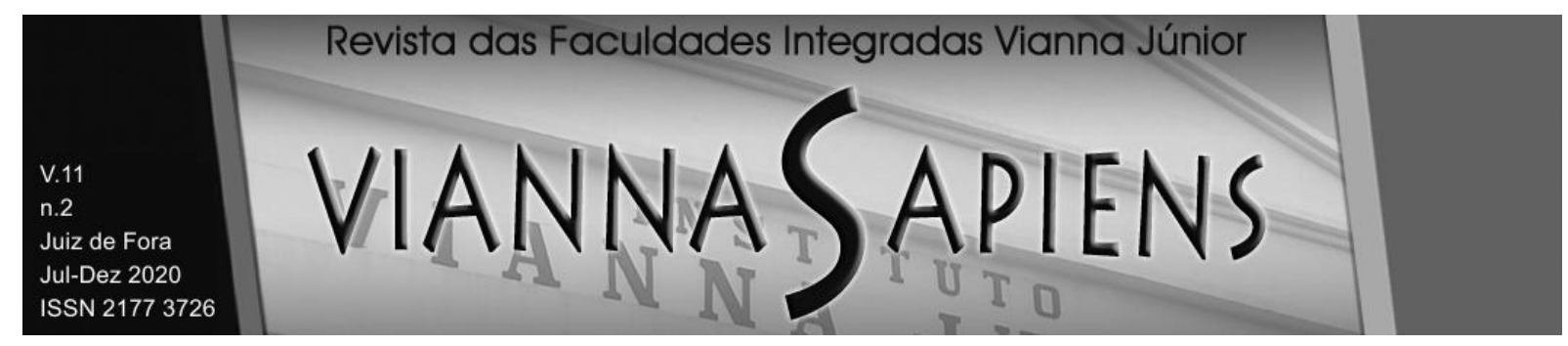

(2020) aponta que os shopping centers vêm obtendo resultados expressivos, tendo registrado em 2019 um crescimento de 7,9\% em faturamento, comparado ao ano anterior. Do total de franquias no mercado, $24,9 \%$ localizam-se em shopping centers em função da facilidade em atrair clientes e fortalecer a marca (ABF, 2020).

O sistema de franquia, ou franchising, proporciona controle e rápida expansão da produção ou comercialização de serviços ou produtos já conhecidos, não sendo necessário investimento expressivo para tal. Além disso, oferece menores riscos para o franqueado ao auxiliar o desenvolvimento do negócio, proporcionando melhor desempenho financeiro (MARICATO, 2017; MELO, BORINI, CUNHA, 2014; NIJMEIJER et al, 2014).

A relação entre empresa franqueadora e o franqueado é estabelecida contratualmente. Sendo o franqueado uma pessoa física ou jurídica associada a uma rede de franquias, sob um conjunto de normas pré-estabelecidas, e a franqueadora aquela que detém direitos sobre uma marca registrada (SIQUEIRA, 2009).

Tal parceria se traduz em resultados positivos para ambos (MAURO, 2010). Isso porque a primeira expande sua atuação através de novas franquias e 0 segundo adquire vantagem competitiva, dada a maior probabilidade de aceitação do cliente de uma marca já consolidada (DAVIES et al, 2011; GHANTOUS; JAOLIS, 2013; MATHEW et al., 2012). Segundo a Associação Brasileira de Franchising (2018), o ano de 2018 foi de crescimento em todas as perspectivas analisadas (Tabela 1).

Tabela 1 - Desempenho do Franchising entre 2014 e 2018.

\begin{tabular}{cccccc}
\hline Ano & Faturamento (Bilhões) & Redes & Unidades & Unidades por rede & Empregos \\
\hline 2014 & 128,876 & 2.942 & 125.641 & 42,7 & 1.096 .859 \\
2015 & 139,593 & 3.073 & 138.343 & 45 & 1.189 .785 \\
2016 & 151,247 & 3.039 & 142.593 & 46,9 & 1.192 .495 \\
2017 & 163,319 & 2.845 & 146.134 & 51,4 & 1.193 .568 \\
2018 & 174,843 & 2.877 & 153.704 & 53,4 & 1.299 .145 \\
\hline
\end{tabular}

Fonte: Adaptado de ABF (2018). 


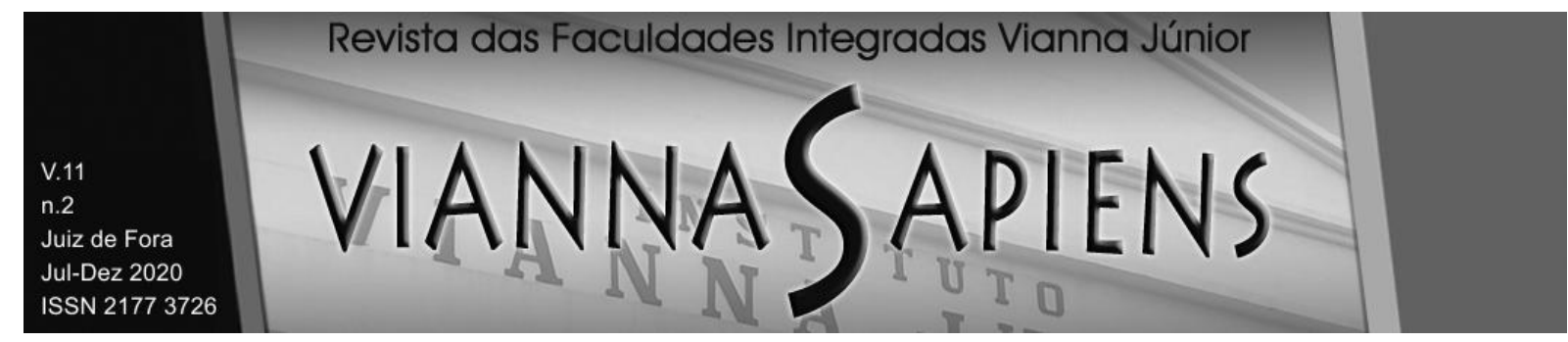

Pode-se destacar, também, o crescimento dobrado no ritmo de expansão. Em 2017 o crescimento do número de unidades foi de 2,4\%, se comparado com 2016, e em 2018, atingiu 5,2\%. Também houve o aumento médio das unidades por rede, 0 que indica a consolidação e amadurecimento do setor, que representa $2,6 \%$ do PIB brasileiro (ABF, 2019). Essa alta se deu devido aos novos modelos de negócios.

Quanto à geração de empregos, o setor apresentou um salto de $8,8 \%$ em 2018. Esse aumento é derivado da retomada de expansão e de novos contratos, intermitentes e temporários (ABF, 2018).

\subsection{Pesquisa de mercado}

A pesquisa de mercado pode ser definida pela identificação, coleta, análise e disseminação de informações de modo sistemático e objetivo. Intenciona compreender os produtos que serão ofertados e a segmentação do negócio, além de verificar o que interfere diretamente no dimensionamento de mercado e nas estratégicas de distribuição e de comercialização (MALHOTRA, 2001).

Para isso, obtêm-se conteúdos mais detalhados e completos, especialmente em função da rápida mudança de comportamento de consumo (ZAMBERLAN, 2008). A pesquisa de mercado (Figura 1) monitora os hábitos dos clientes e suas expectativas (POLIGNANO; DRUMOND, 2001; COBRA, 1992).

Figura 1 - Questões fundamentais da pesquisa mercadológica.

\begin{tabular}{|c|c|}
\hline Quem? & \multicolumn{1}{|c|}{ Descreve o consumidor. } \\
\hline Qual? & $\begin{array}{l}\text { - Aponta quais produtos ou serviços atendem às } \\
\text { necessidades. }\end{array}$ \\
\hline Onde? & $\begin{array}{l}\text { - Indica o local no qual o consumidor faz suas } \\
\text { compras. }\end{array}$ \\
\hline Quando? & - Define o periodo/horário de compra. \\
\hline Quanto? & $\begin{array}{l}\text { - Indica a quantidade adquirida, o formato e } \\
\text { acondicionamento. }\end{array}$ \\
\hline Como? & $\begin{array}{l}\text { - Mostra que utilização é feita do produto ou } \\
\text { serviço. }\end{array}$ \\
\hline
\end{tabular}

Fonte: Adaptado de Cobra (1992). 


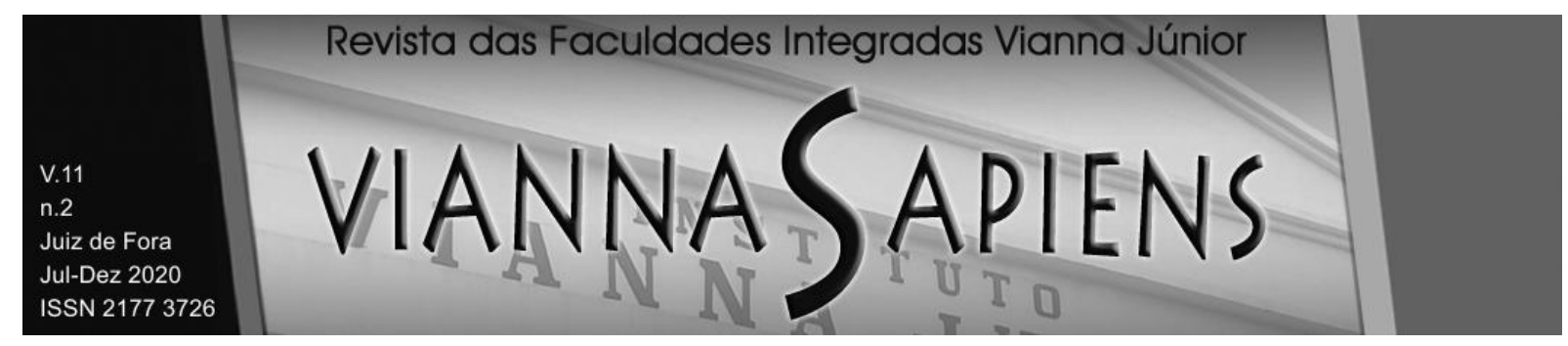

Dessa forma, de posse de mais informações sobre o empreendimento, há maior clareza e credibilidade ao avaliar as oportunidades, o que torna as decisões mais objetivas (FERREIRA, 2009). O estudo de mercado evidencia, como um todo, a aceitabilidade do negócio e o seu sucesso (CASAROTTO FILHO, 2014).

Decisões equivocadas ocorrem ao se apurar, inadequadamente, os cenários de atuação, interferindo nas projeções de curto, médio e longo prazo (ZAMBERLAN, 2008; COBRA, 1992). Uma análise específica requer amplo conhecimento do negócio, sendo imprescindível dispor de dados qualificados.

\subsection{Demonstrações contábeis e análise de viabilidade econômico-financeira}

As demonstrações contábeis são fundamentais para avaliação da saúde financeira da empresa, bem como os retornos obtidos a partir de investimentos (ASSAF NETO, 2012). Os principais envolvidos no empreendimento passam a ter ciência dos resultados apurados (GOMES, LAURINDO, 2014).

Uma das ferramentas mais importantes é o fluxo de caixa, de fácil compreensão e que capta rapidamente o fluxo de informações (ROSS et al, 2010; SILVA, 2008). O Retorno sobre o Capital Investido (ROIC) também é essencial, uma vez que quantifica o desempenho operacional da empresa (ASSAF NETO, 2012). As definições das ferramentas encontram-se no Quadro 1.

\section{Quadro 1 - Demonstrações contábeis - Retorno sobre o capital investido (ROIC) e Demonstração de Fluxo de Caixa (DFC).}

\begin{tabular}{|c|c|c|c|}
\hline Método & Definição & Fórmula & \multicolumn{1}{c|}{ Variáveis } \\
\hline $\begin{array}{c}\text { Retorno sobre o } \\
\text { Capital Investido } \\
\text { (ROIC) }\end{array}$ & $\begin{array}{c}\text { Desempenho operacional efetivo da } \\
\text { organização calculado pela divisão entre o } \\
\text { lucro operacional líquido menos os impostos } \\
\text { ajustados e o capital investido (ASSAF } \\
\text { NETO, 2012; COPELAND et al., 2002; } \\
\text { VANSTRACEELE, TOIT, 2014; } \\
\text { GREENBLATT, 2010). }\end{array}$ & $\begin{array}{c}\text { ROIC = (LL- } \\
\mathrm{IMP}) / \mathrm{Cl} \text { - }\end{array}$ & $\begin{array}{l}\text { Lucro } \\
\text { líquido; } \\
\text { IMP = Impostos } \\
\text { ajustados; } \\
\mathrm{Cl}=\text { Capital } \\
\text { Investido. }\end{array}$ \\
\hline $\begin{array}{c}\text { Demonstrações de } \\
\text { fluxo de caixa (DFC) }\end{array}$ & $\begin{array}{c}\text { Instrumento principal de gestão financeira } \\
\text { que planeja, analisa e controla os }\end{array}$ & - & - \\
\hline
\end{tabular}




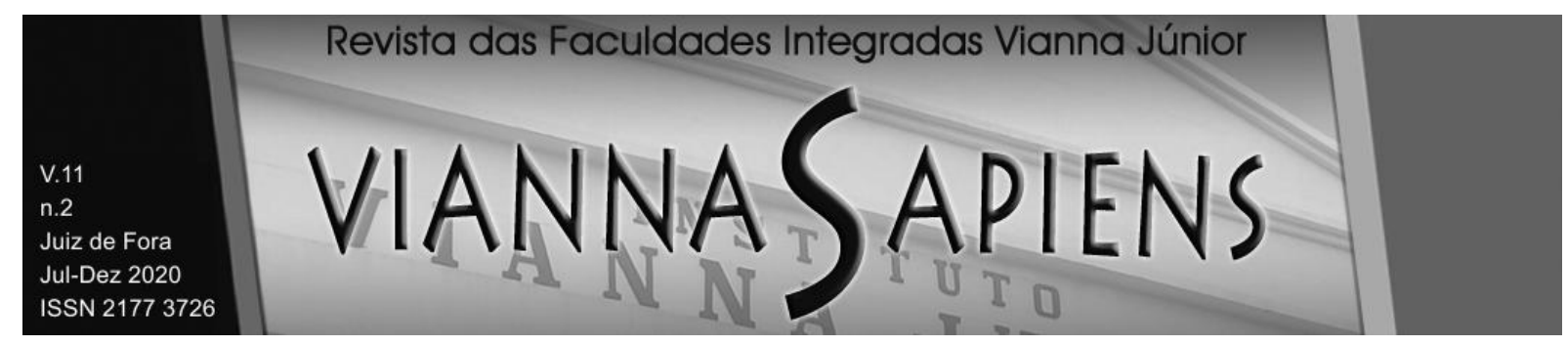

investimentos e as despesas por período

(SILVA, 2008; HOJI, 2010).

Fonte: Autoria própria.

O índice de mortalidade das empresas, em muitas vezes, está associado a uma gestão ineficaz (HALL et al, 2012). Por isso, a análise de viabilidade deve ser implementada com métodos e técnicas que demonstrem, claramente, o retorno sobre o investimento, fornecendo subsídios para a tomada de decisão, que deve ser criteriosa e embasada em apreciações lógicas (HOJI, 2010).

A avaliação, de acordo com Ferreira (2009), evidencia a análise de fluxo de caixa da vida útil, visando mensurar a rentabilidade do projeto, o prazo de payback, a taxa interna de retorno e a relação benefício/custo (Quadro 2).

\section{Quadro 2 - Análise de viabilidade econômico-financeira.}

\begin{tabular}{|c|c|c|c|}
\hline Método & Definição & Fórmula & Variáveis \\
\hline $\begin{array}{l}\text { Valor } \\
\text { presente } \\
\text { líquido } \\
\text { (VPL) }\end{array}$ & $\begin{array}{c}\text { Atualização de fluxos de caixa de } \\
\text { receitas ou faturamentos, custos ou } \\
\text { despesas e lucros operacionais para } \\
\text { certo planejamento, aplicando a Taxa } \\
\text { Mínima de Atratividade. Quando o VPL } \\
\text { é positivo, aponta que o investimento é } \\
\text { viável (FERREIRA, 2009; KASSAI et } \\
\text { al., 2000; SOUZA, 2003; PILÃO, } \\
\text { HUMMEL, 2003). }\end{array}$ & $V P L=-I+\sum_{t=1}^{n} \frac{F C t}{(1+i)^{t}}$ & $\begin{array}{l}\text { VPL = Valor Presente } \\
\text { Líquido } \\
\text { I = Capital Investido; } \\
\text { FCt = Fluxo de Caixa no } \\
\text { tempo estipulado; } \\
\text { i = Taxa Mínima de } \\
\text { Atratividade; } \\
\text { t = Tempo estipulado. }\end{array}$ \\
\hline $\begin{array}{l}\text { Taxa } \\
\text { interna de } \\
\text { retorno } \\
(\mathrm{TIR})\end{array}$ & $\begin{array}{l}\text { Cálculo da taxa de retorno que zera o } \\
\text { Valor Presente dos Fluxos de caixa. } \\
\text { Quando seu valor é maior que a taxa } \\
\text { mínima de atratividade, atesta-se a } \\
\text { viabilidade do negócio (WARREN; } \\
\text { REEVE; FESS, 2001; SAMANEZ, } \\
\text { 2007; DHAVALE; SARKIS, 2017; } \\
\text { SPERTINO; LEO; COCINA, 2013). }\end{array}$ & $0=-I+\sum_{t=1}^{n} \frac{F C t}{(1+i)^{t}}$ & $\begin{array}{l}\text { I = Capital Investido; } \\
\text { FCt = Fluxo de Caixa no } \\
\text { tempo estipulado; } \\
\text { i = Taxa Mínima de } \\
\text { Atratividade; } \\
\text { t = Tempo estipulado. }\end{array}$ \\
\hline Payback & $\begin{array}{l}\text { Tempo necessário para que o capital } \\
\text { inicial investido seja recuperado e } \\
\text { serve como indicador do grau de risco } \\
\text { do projeto (KANTAMA et al., 2015; } \\
\text { FERREIRA, 2009; HOSS et al., 2012). }\end{array}$ & $V P L=-I+\sum_{t=1}^{t=P B D} \frac{F C t}{(1+i)^{t}}=0$ & $\begin{array}{l}\text { VLP = Valor Presente } \\
\text { Líquido } \\
\text { I = Capital Investido; } \\
\text { FCt = Fluxo de Caixa no } \\
\text { tempo estipulado; } \\
\text { PBD = Payback } \\
\text { Descontado } \\
\text { i = Taxa Mínima de } \\
\text { Atratividade; } \\
\text { t = Tempo estipulado. }\end{array}$ \\
\hline
\end{tabular}

Fonte: Autoria própria. 


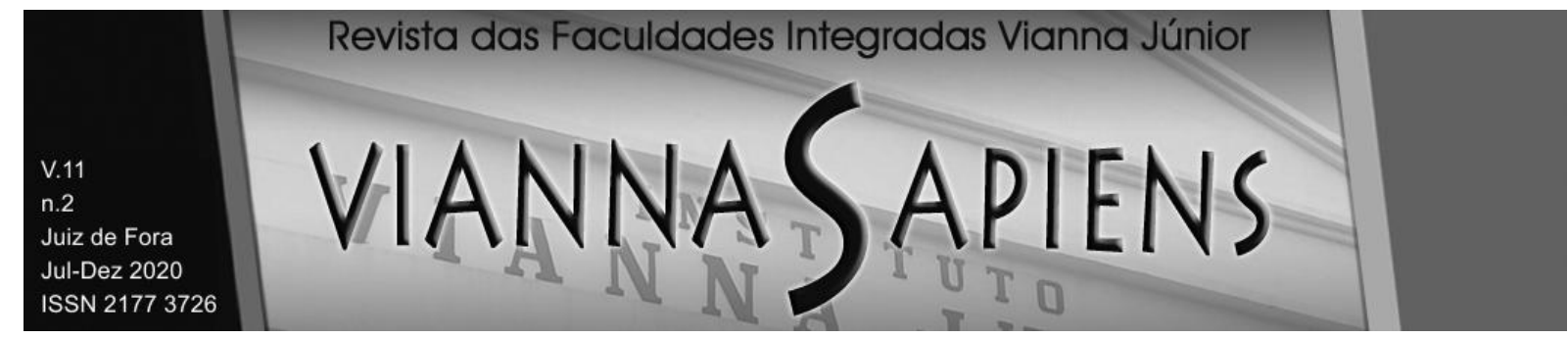

Basicamente, tais ferramentas apontam se o plano de desembolso é factível e se se traduz em retorno esperado (BROM, BALIAN, 2007). São desenvolvidos cenários que simulam crescimento econômico, mudanças de taxas de juros e outras variáveis, de modo a se avaliar possíveis impactos (BORDEAUX-RÊGO, 2013).

No âmbito econômico, a avaliação é acompanhada por um estudo de mercado (micro e macroeconômico), tamanho do projeto, localização, engenharia do projeto, receitas diretas e indiretas e custos (FERREIRA, 2009). E é importante que o horizonte de tempo analisado esteja alinhado com a dinâmica do negócio (FONSECA, 2012).

\section{METODOLOGIA}

Este estudo é uma pesquisa aplicada que visa a solução de problemas concretos e práticos (GIL, 2010; ZANELLA, 2009). Mais especificamente, analisa a viabilidade econômico-financeira para a implementação de uma franquia de artigos de presentes e decoração, configurando-se como um estudo de caso descritivo, com levantamento detalhado de informações (YIN, 2005; RICHARDSON et al, 2011).

Para isso, foram usados dados primários e secundários, quali-quantitativos, obtidos por análise documental de relatórios disponibilizados pela franqueadora (LAKATOS, MARCONI, 2011). As fases do estudo estão apresentadas no Quadro 3.

Quadro 3 - Etapas de realização do estudo.

\begin{tabular}{|c|c|}
\hline Fase & Desdobramentos \\
\hline Pesquisa de mercado & Compreender produto, consumidores e oportunidades do negócio. \\
\hline $\begin{array}{c}\text { Demonstrações } \\
\text { contábeis }\end{array}$ & $\begin{array}{c}\text { Orçar o projeto e, com base no investimento, fazer as projeções por DFC } \\
\text { e ROIC. }\end{array}$ \\
\hline $\begin{array}{c}\text { Viabilidade econômico- } \\
\text { financeira }\end{array}$ & Cálculo de VPL, TIR e payback. \\
\hline Decisão de investimento & $\begin{array}{c}\text { Com base nos dados quantitativos, das demonstrações contábeis e dos } \\
\text { pesquisa de mercado, empreendedor decide pelo investimento. }\end{array}$ \\
\hline
\end{tabular}

Fonte: Autoria própria. 


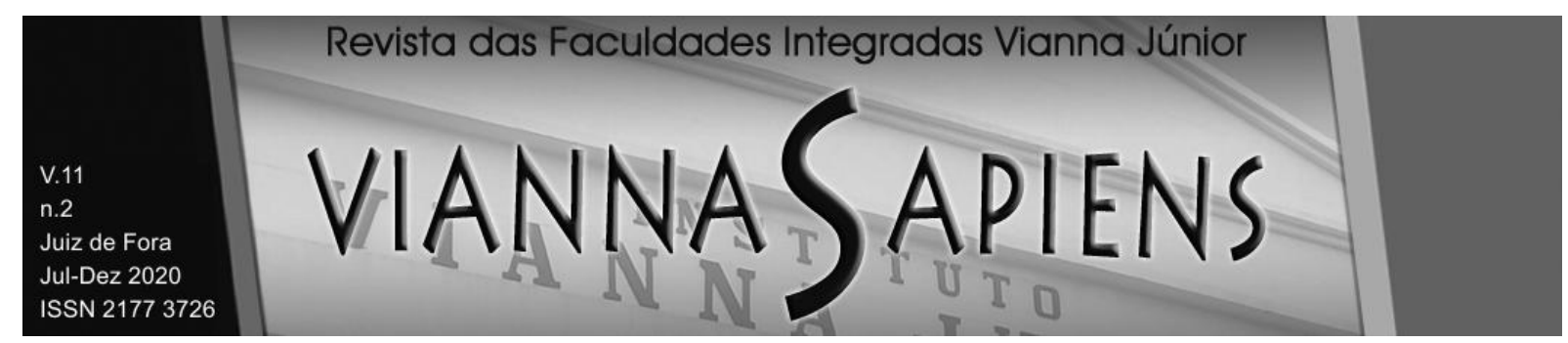

Também foram estruturados os dados qualitativos da pesquisa de mercado. Através deles, produtos e serviços foram detalhados de modo que se compreendessem o contexto e as característica de atuação da empresa. Em seguida, foram levantados os investimentos necessários para a implementação do negócio.

Os custos, despesas e receitas foram projetados com auxílio da ferramenta Microsoft Excel®. A partir deles, foram apurados: DFC, ROIC, VPL, TIR e payback. Para isso, algumas premissas de cálculos foram adotadas, tomando como base o desempenho histórico de outros franqueados. Por fim, os dados foram interpretados qualitativa e quantitativamente, de modo que se avaliou a viabilidade econômicofinanceira do investimento.

\section{RESULTADOS E DISCUSSÕES}

Primeiramente, foram levantadas informações sobre as condições de atuação e demais características de operação do negócio avaliado. A empresa franqueadora foi fundada em 1991 e se destaca como líder do segmento de fun design, lançando até 400 novos itens, anualmente. A marca conta com 254 operações, sendo 242 delas localizadas em shoppings, além de deter canais de e-commerce e atender lojas multimarcas. Em 2019, a rede cresceu 10\% e faturamento superior a $\mathrm{R} \$ 220$ milhões.

A cidade considerada possui a 6 a $^{\mathbf{a}}$ maior economia da Bahia, com participação de 2,29\% no Produto Interno Bruto (PIB) estadual, crescendo $340 \%$ nos últimos dez anos, dada a expansão de vários setores (VITÓRIA DA CONQUISTA, 2015). A perspectiva é acender mais uma posição no ranking econômico do estado.

$\mathrm{Na}$ cidade era comum a venda de itens da franquia em lojas multimarcas, 0 que contou como ponto positivo na análise de mercado. A marca possui forte ligação com seus clientes, principalmente o público mais jovem. O Shopping Boulevard, 


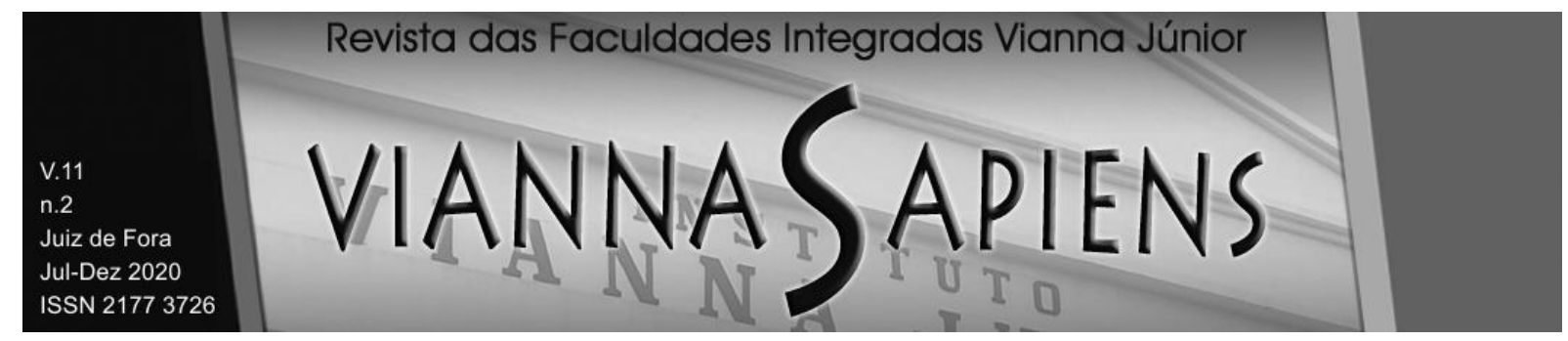

onde seria instalado o empreendimento, foi inaugurado em Abril de 2018, localizado em área nobre, atendendo público classe $A$ e $B$, com renda familiar superior a $R \$$ $8.641,00$.

Informações de vendas e faturamento de lojas instaladas em cidades com porte econômico similar à loja de Vitória da Conquista - BA foram disponibilizadas como forma de traçar comparativos e auxiliar a decisão de investimento. Custos de instalação foram negociados pela empresa franqueadora diretamente com a administração do shopping, reduzindo valor do aluguel e da manutenção do espaço.

\subsection{Premissas adotadas}

Para a implementação da franquia foi necessário um investimento inicial de $R \$ 321.496,00$. Os custos detalhados desse investimento constam na Tabela 2.

Tabela 2 - Investimento inicial.

\begin{tabular}{cc}
\hline Descrição & Custo \\
\hline Taxa Franquia & $\mathrm{R} \$ 30.000,00$ \\
Obras + mobiliário & $\mathrm{R} \$ 244.664,00$ \\
Comunicação Visual & $\mathrm{R} \$ 3.500,00$ \\
Software LINX & $\mathrm{R} \$ 2.332,00$ \\
Projeto & $\mathrm{R} \$ 4.000,00$ \\
Equipamentos & $\mathrm{R} \$ 7.000,00$ \\
Contrato de Direito de Uso (CDU) - ponto comercial & $\mathrm{R} \$ 30.000,00$ \\
\hline TOTAL & $\mathbf{R} \$ \mathbf{3 2 1 . 4 9 6 , 0 0}$ \\
\hline
\end{tabular}

Fonte: Autoria própria.

Baseado no histórico de vendas, cada mês do ano apresenta um fator peso (Tabela 3). Esse fator é multiplicado pela média de faturamento anual, que equivale à projeção de faturamento de cada mês analisado.

Tabela 3 - Fator de faturamento de cada mês.

\begin{tabular}{cc}
\hline Mês & Fator de faturamento \\
\hline Janeiro & 1,054 \\
Fevereiro & 0,863 \\
Março & 0,872
\end{tabular}




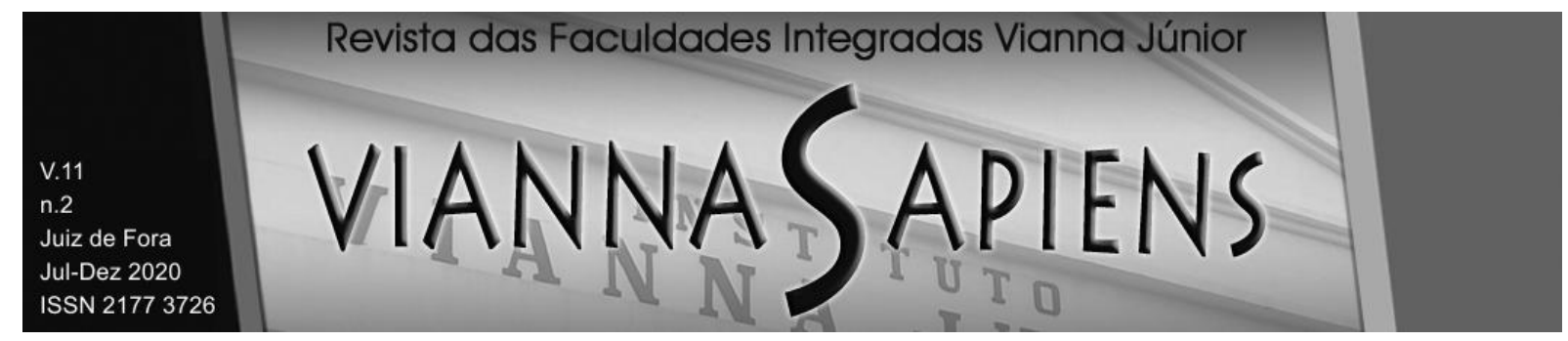

\begin{tabular}{cc} 
Abril & 0,634 \\
Maio & 0,972 \\
Junho & 1,032 \\
Julho & 0,790 \\
Agosto & 1,031 \\
Setembro & 0,622 \\
Outubro & 0,749 \\
Novembro & 0,864 \\
Dezembro & 2,518 \\
\hline Total & $\mathbf{1 2 , 0 0}$ \\
\hline
\end{tabular}

Fonte: Autoria própria, com base em dados cedidos pela empresa franqueadora.

Quanto aos impostos e tributações exigidos em leis, também foi definido como premissa o percentual da alíquota de cada um deles. A Tabela 4 apresenta o percentual de cada tributação e a alíquota do Simples Nacional, em relação ao faturamento bruto anual.

Tabela 4 - Simples nacional.

\begin{tabular}{cccccccc}
\hline Receita Bruta Anual & Alíquota & IRPJ & CSLL & COFINS & PIS/PASEP & INSS & ICMS \\
\hline Até $\mathrm{R} \$ 180.000,00$ & $4,00 \%$ & $0,00 \%$ & $0,00 \%$ & $0,00 \%$ & $0,00 \%$ & $2,75 \%$ & $1,25 \%$ \\
de $\mathrm{R} \$ 180.000,01$ a $\mathrm{R} \$ 360.000,00$ & $5,47 \%$ & $0,00 \%$ & $0,00 \%$ & $0,86 \%$ & $0,00 \%$ & $2,75 \%$ & $1,86 \%$ \\
de $\mathrm{R} \$ 360.000,01$ a $\mathrm{R} \$ 540.000,00$ & $6,84 \%$ & $0,27 \%$ & $0,31 \%$ & $0,95 \%$ & $0,23 \%$ & $2,75 \%$ & $2,33 \%$ \\
de $\mathrm{R} \$ 540.000,01$ a $\mathrm{R} \$ 720.000,00$ & $7,54 \%$ & $0,35 \%$ & $0,35 \%$ & $1,04 \%$ & $0,25 \%$ & $2,99 \%$ & $2,56 \%$ \\
de $\mathrm{R} \$ 720.000,01$ a $\mathrm{R} \$ 900.000,00$ & $7,60 \%$ & $0,35 \%$ & $0,35 \%$ & $1,05 \%$ & $0,25 \%$ & $3,02 \%$ & $2,58 \%$ \\
de $\mathrm{R} \$ 900.000,01$ a $\mathrm{R} \$ 1.080 .000,00$ & $8,28 \%$ & $0,38 \%$ & $0,38 \%$ & $1,15 \%$ & $0,27 \%$ & $3,28 \%$ & $2,82 \%$ \\
de $\mathrm{R} \$ 3.420 .000,01$ a $\mathrm{R} \$ 3.600 .000,00$ & $11,61 \%$ & $0,34 \%$ & $0,34 \%$ & $1, \ldots 0 \%$ & $0,38 \%$ & $4, \ldots 6 \%$ & $3,95 \%$ \\
\hline
\end{tabular}

Fonte: Autoria própria, com base em dados fornecidos pelo Simples Nacional.

Para o primeiro ano, foi estimado pela empresa franqueadora um faturamento de $\mathrm{R} \$ 70.000,00$ por mês. Para os anos seguintes, foi adotado como previsão um aumento de $5 \%$ no faturamento, em relação ao ano anterior, conforme Tabela 5.

Tabela 5 - Previsão de faturamento anual (média por mês).

\begin{tabular}{cc}
\hline Ano & Faturamento (R\$) \\
\hline Primeiro & 70.000 \\
Segundo & 73.500 \\
Terceiro & 77.175 \\
Quarto & 81.034
\end{tabular}




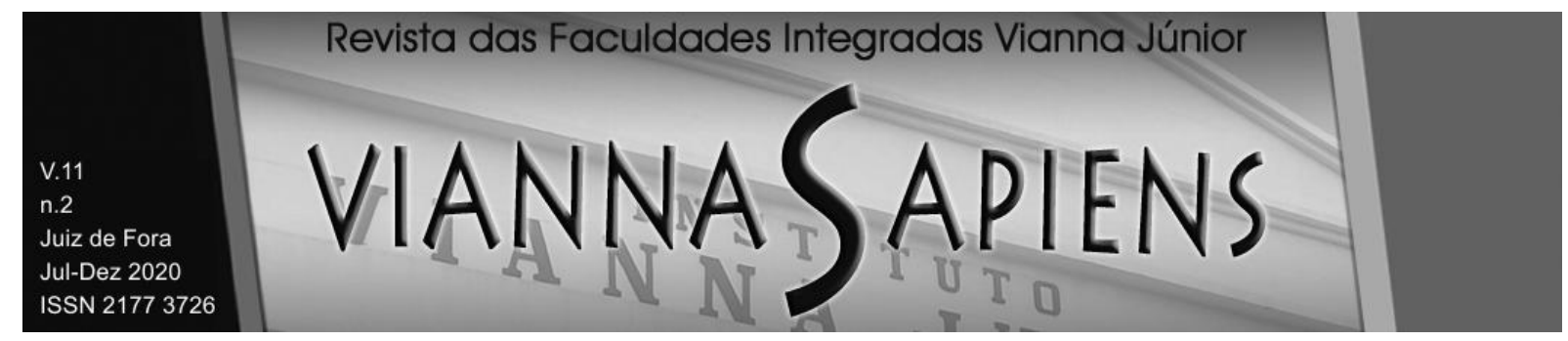

Quinto

85.085

Fonte: Autoria própria, com base em dados cedidos pela empresa franqueadora.

A Tabela 6 mostra os percentuais de tributação pela franquia na Bahia.

Tabela 6 - Percentuais de tributação.

\begin{tabular}{cccccc}
\hline UF & $\begin{array}{c}\text { MKP CD } \\
\left(^{*}\right)\end{array}$ & $\begin{array}{c}\text { MPK 3os } \\
\left({ }^{* *}\right)\end{array}$ & $\begin{array}{c}\text { Despesa com ST } \\
\left({ }^{* *}\right)\end{array}$ & $\begin{array}{c}\text { Despesa com Difa } \\
\left({ }^{* * *}\right)\end{array}$ & Participação de ST \\
\hline BA & 3 & 2,69 & $1,85 \%$ & $2,61 \%$ & $19 \%$ \\
\hline
\end{tabular}

Fonte: Autoria própria, com base em dados cedidos pela empresa franqueadora.

Legenda: (*) MKP CD: Mark-up centro de distribuição; $\left(^{* \star}\right)$ MKP $30 s:$ Mark-up de terceiros; $\left(^{* \star *}\right)$ ST:

Substituição Tributária; $\left.{ }^{(* \star *}\right)$ Difa: Diferencial de Alíquota.

No que se refere aos custos com mão de obra, considerando o período de janeiro a novembro, estipulou-se um quadro de funcionários de 6 pessoas: 1 gerente; 4 vendedores e 1 estoquista. Excepcionalmente no mês de dezembro, fazse necessária a contratação de mais um vendedor, totalizando 7 trabalhadores.

Excetuando o estoquista, os salários são compostos por: Piso salarial, conforme convenção coletiva do sindicato; Comissões de acordo com o faturamento médio mensal; e Premiações (com valores variáveis). A comissão é acrescentada ao gerente e aos vendedores, representando $1 \%$ do faturamento médio mensal. As premiações também são aplicadas apenas para os vendedores e para o gerente, sendo $R \$ 80,00$ para cada vendedor e $R \$ 160,00$ para o gerente, semanalmente.

Além disso, os trabalhadores contam com vale transporte no valor de $R \$ 3,80$. Aos vendedores é concedido ticket refeição no valor de $R \$ 240,00$ no total (ticket diário de $\mathrm{R} \$ 15,00)$. Também foi estimado gasto de um salário mínimo para o contador.

A Tabela 7 mostra os custos com aluguel, considerando reajuste de $8 \%$ ao longo dos anos, conforme o Índice Geral de Preços do Mercado (IGP-M). Estipula-se que o aluguel corresponde a $5 \%$ do faturamento bruto registrado em cada mês. $O$ Shopping cobra aluguel dobrado em dezembro. 


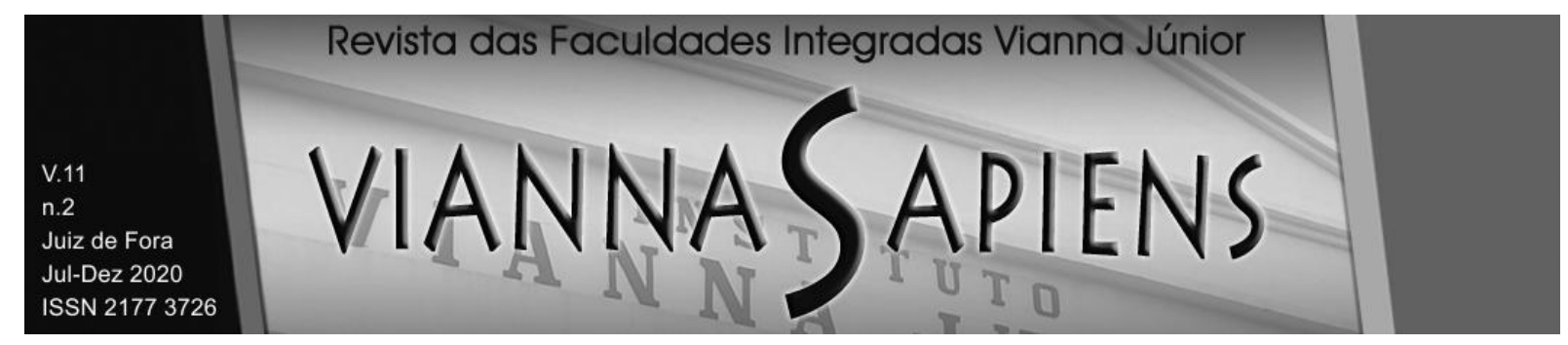

Tabela 7 - Custo de aluguel.

\begin{tabular}{cccccc}
\hline & $1^{\circ}$ ano & $2^{\circ}$ ano & $3^{\circ}$ ano & $4^{\circ}$ ano & $5^{\circ}$ ano \\
\hline Aluguel por $\mathrm{m}^{2}$ & $\mathrm{R} \$ 70,00$ & $\mathrm{R} \$ 75,60$ & $\mathrm{R} \$ 81,65$ & $\mathrm{R} \$ 88,18$ & $\mathrm{R} \$ 95,23$ \\
Aluguel (mensal) & $\mathrm{R} \$ 3.058,30$ & $\mathrm{R} \$ 3.302,96$ & $\mathrm{R} \$ 3.567,20$ & $\mathrm{R} \$ 3.852,58$ & $\mathrm{R} \$ 4.160,78$ \\
\hline
\end{tabular}

Fonte: Autoria própria.

Além disso, é cobrado $R \$ 65,00 / \mathrm{m}^{2}$ de condomínio, totalizando $R \$ 2.839,85$. Para o fundo do shopping, destinado para pagamento de propaganda, foi considerado $20 \%$ do aluguel pago. O valor de Imposto sobre a Propriedade Predial e Territorial Urbana (IPTU) adotado foi de $R \$ 336,25$. Gastos com ar condicionado foi de $R \$ 600,00$. Como custos internos da loja foram definidos luz, telefone e demais despesas operacionais. $\mathrm{O}$ custo fixo de cada fator é mostrado na Tabela 8.

Tabela 8 - Custos internos e despesas operacionais.

\begin{tabular}{cc}
\hline Descrição & Custo \\
Luz & $\mathrm{R} \$ 700,00$ \\
Telefone & $\mathrm{R} \$ 268,06$ \\
Seguro & $\mathrm{R} \$ 220,00$ \\
Limpeza & $\mathrm{R} \$ 50,00$ \\
Vitrine & $\mathrm{R} \$ 120,00$ \\
Material Escritório, Papel de Seda, Plástico Bolha & $\mathrm{R} \$ 30,00$ \\
Manutenção Ar Condicionado & $\mathrm{R} \$ 120,00$ \\
Manutenção Sistema Elétrico & $\mathrm{R} \$ 50,00$ \\
Assistência Jurídica & - \\
PCMSO / PPRA & $\mathrm{R} \$ 96,00$ \\
Escritório Central de Arrecadac̃a e Distribuição (ECAD) & $\mathrm{R} \$ 30,00$ \\
E-Learning ( $\left.{ }^{*}\right)+$ Visita de Consultoria & $\mathrm{R} \$ 119,00$ \\
Software (Linux) + Disruptiva (**) & $\mathrm{R} \$ 536,50$ \\
Internet & - \\
GET NET (***) FIXO - ref. a mensalidade & $\mathrm{R} \$ 83,00$ \\
GET NET GPRS (móvel) - ref. a mensalidade & $\mathrm{R} \$ 34,50$ \\
\hline
\end{tabular}
Fonte: Autoria própria.

Legenda: $\left(^{*}\right)$ E-Learning são treinamentos online voltados para gerentes e vendedores. Consultoria é relacionado à consultoria externa para ajudar na gestão da franquia; $\left.{ }^{* *}\right)$ Disruptiva é o software de gestão; $\left(^{* * *}\right)$ GET NET FIXO e GET NET GPRS é a máquina de passar cartão débito e crédito, porém a GPRS passa em outros lugares por ser móvel e a fixa só pode ser usada na loja instalada.

A Tabela 9 descreve os custos variáveis para manutenção da loja. 


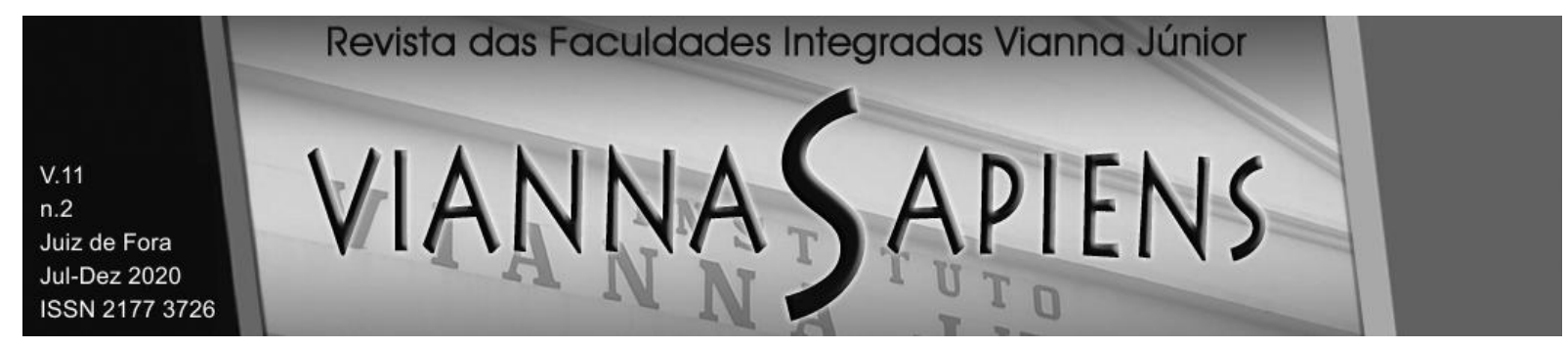

Tabela 9 - Custos variáveis.

\section{Descrição}

Reposição Estoque CD (Mark-up)

Reposição Estoque Terceiros (Mark-up)

DESPESA COM ST (\% sobre o valor comprado de produtos com ST)

DESPESA COM DIFA (\% sobre o valor comprado de produtos sem ST)

Perdas e Outras Despesas

Desp. Transporte

Desp. Embalagens - (2,5\% x faturamento mensal)

Royalties R1 (5\% x faturamento mensal)

Royalties R2 (42,9\% da compra CD mensal)

Fundo de Publicidade (sobre faturamento mensal)

Desconto de Cartões (80\% Faturamento x 1,86\% - GETNET)

Tarifa Bancária

Descontos diversos ( $p /$ pagamentos à vista)

Participação da Fábrica - Centro de Distribuição (CD)

Participação dos fornecedores

Fonte: Autoria própria, com base em informações repassadas pela franqueadora.

Valores

3

2,69

$1,90 \%$

$2,61 \%$

$0,30 \%$

$0,00 \%$

$2,50 \%$

$5 \%$

$42,90 \%$

$2,00 \%$

$1,49 \%$

$\mathrm{R} \$ 50,00$

$\mathrm{R} \$ 100,00$

$95,00 \%$

$5,00 \%$

Considerando os valores de faturamento, estimados para os 5 primeiros anos (Tabela 5), e os percentuais das faixas do Simples Nacional (Tabela 4) e demais percentuais de tributação (Tabela 6), temos uma estimativa de percentuais a serem pagos ao longo dos anos (Tabela 10).

Tabela 10 - Projeção de tributação ao longo dos anos.

\begin{tabular}{lccccc}
\hline \multicolumn{1}{c}{ Descrição } & Ano 1 & Ano 2 & Ano 3 & Ano 4 & Ano 5 \\
\hline SIMPLES (COFINS,PIS,CS,IR,INSS(pl)ICMS) & $7,60 \%$ & $7,60 \%$ & $8,28 \%$ & $8,28 \%$ & $8,28 \%$ \\
Valor de percentual de ST no MIX de ProdutoS & $19 \%$ & $19 \%$ & $19 \%$ & $19 \%$ & $19 \%$ \\
SIMPLES (COFINS,PIS,CS,IR,INSS(pl)ICMS c/ desconto da ST) & $7,12 \%$ & $7,12 \%$ & $7,75 \%$ & $7,75 \%$ & $7,75 \%$ \\
\hline
\end{tabular}

Fonte: Autoria própria.

Dessa forma, foram descritos todos os itens que serão considerados como base para os cálculos considerados no fluxo de caixa para os cinco anos.

\subsection{Dados para cálculos}

Os dados para cálculo foram classificados em três categorias: Custos de Mão de obra (Quadro 1); Custos Fixos (Quadro 2); e, Custos variáveis (Quadro 3). Os métodos de cálculo adotados em cada um deles. 


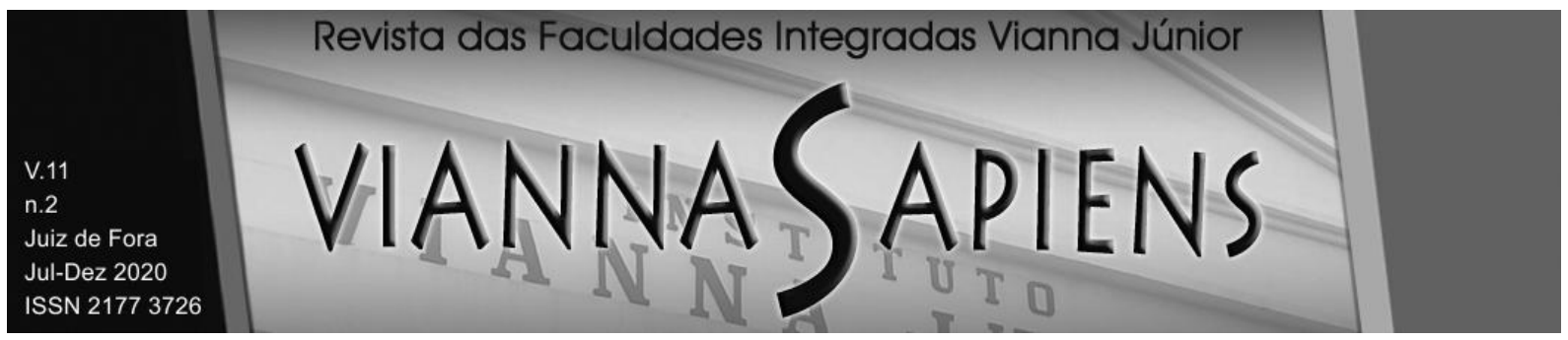

Quadro 1 - Cálculos da mão de obra.

\begin{tabular}{|c|c|}
\hline Variável & Cálculo \\
\hline Gerente & $\begin{array}{l}\text { Piso do sindicato adotado como premissa + (Faturamento bruto mensal } x \\
\text { Premissa de percentual de comissão) }\end{array}$ \\
\hline Vendedores & $\begin{array}{l}\text { Considera o maior valor entre: } \\
\text { a. (Faturamento bruto mensal } x \text { Percentual de comissão) + (Quantidade } \\
\text { de vendedores } x \text { valor de premiações) } \\
\text { b. Quantidade de vendedores x piso salarial }\end{array}$ \\
\hline Estoquista & (Quantidade de estoquistas x Piso salarial) + Premiações \\
\hline $\begin{array}{l}\text { Equipe para Natal } \\
\text { (vendedores extras) }\end{array}$ & $\begin{array}{l}\text { Considera o maior valor entre: } \\
\text { a. Quantidade de vendedor extra no mês de dezembro x Piso salarial } \\
\text { b. Quantidade de vendedor extra x (Faturamento bruto mensal/ } \\
\text { Quantidade de vendedores total) x Percentual de comissão total }\end{array}$ \\
\hline DSR & $\begin{array}{l}\text { (Faturamento bruto do mês } x \text { somatório das comissões) / (Dias úteis } x \\
\text { Quantidade de domingos e feriados) }\end{array}$ \\
\hline FGTS & $8 \% \times(K+$ premiação gerente $)$ \\
\hline Férias & $(\mathrm{K}+$ premiação gerente $) /(12 \times 0,33)$ \\
\hline $13^{\circ}$ salário & $(\mathrm{K}+$ premiação gerente) $/ 12$ \\
\hline Premiação gerente & Valor da premiação $x$ quantidade de semanas \\
\hline Vale transporte & $\begin{array}{l}\left(\mathrm{n}^{\circ} \text { total de funcionários } \times \text { valor do vale transporte } \times 2 \times 26\right)-\left(\mathrm{n}^{\circ} \text { total de }\right. \\
\text { funcionários } \times 26 \times 2 \times \text { valor vale transporte } \times 6 \%)\end{array}$ \\
\hline Ticket refeição & Quantidade de vendedores $\mathrm{x} \mathrm{n}^{\circ}$ de dias $\mathrm{x}$ valor do ticket \\
\hline
\end{tabular}

No vale transporte foram considerados 26 dias de trabalho para cálculo e deduzido $6 \%$, debitado no salário do empregado. Abaixo estão definidos os cálculos da categoria Custos Fixos (Quadro 2). 


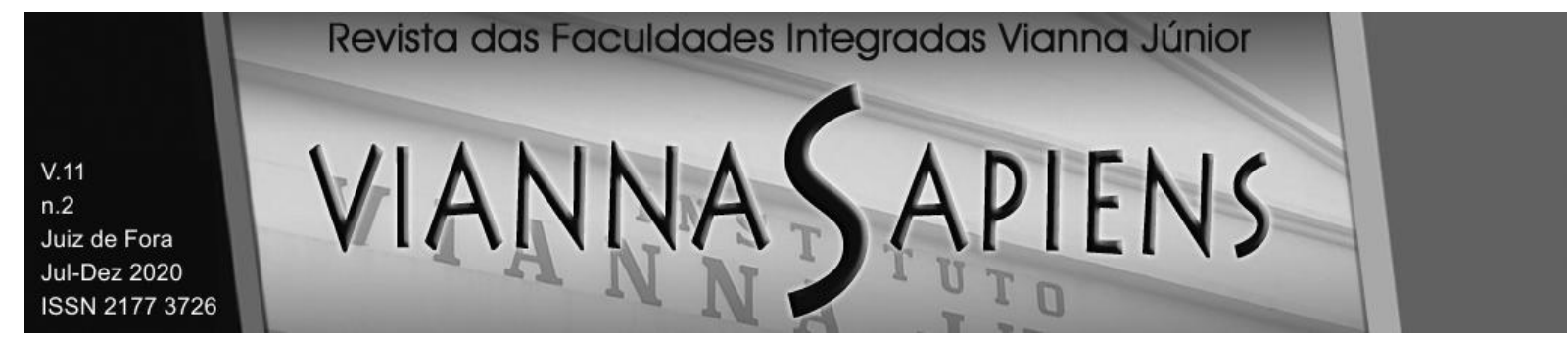

Quadro 2 - Cálculos dos custos fixos.

\begin{tabular}{|c|l|}
\hline Variável & \multicolumn{1}{c|}{ Cálculo } \\
\hline Aluguel & $\begin{array}{l}\text { Considera o maior valor entre: } \\
\text { a. } 5 \% \text { do faturamento bruto do mês. } \\
\text { b. Valor do aluguel por } \mathrm{m}^{2} \text { multiplicado pela metragem da loja. }\end{array}$ \\
\hline Valor Condomínio & Metragem da loja $\left(\mathrm{m}^{2}\right)$ multiplicado pelo valor do condomínio \\
\hline Fundo do Shopping & $\begin{array}{l}\text { Valor do aluguel multiplicado pelo fundo promocional do shopping } \\
\text { (isto é, \% do aluguel mínimo) }\end{array}$ \\
\hline Despesas IPTU & Valor estabelecido como premissa para IPTU \\
\hline Despesas Ar Condicionado & Valor estabelecido como premissa para ar condicionado \\
\hline Telefone & Valor estabelecido como premissa para telefone \\
\hline Luz e energia & Valor estabelecido como premissa para luz \\
\hline Despesas Operacionais & $\begin{array}{l}\text { Somatório de todas as premissas adotadas como despesas } \\
\text { operacionais }\end{array}$ \\
\hline Contador & Valor estabelecido como premissa para pagamento do contador \\
\hline
\end{tabular}

Fonte: Autoria própria.

Por fim, os cálculos dos Custos Variáveis estão detalhados no Quadro 3.

\begin{tabular}{|c|c|}
\hline & \\
\hline Variável & Cálculo \\
\hline $\begin{array}{l}\text { Reposição de estoque } \\
\text { (Centro de Distribuição) }\end{array}$ & $\begin{array}{l}\text { [(Faturamento bruto mensal } x \% \text { definido como premissa de } \\
\text { participação da fábrica CD) / premissa reposição estoque CD (Mark- } \\
\text { up)]/ ( } 1 \text { + premissa royalties } 2)\end{array}$ \\
\hline Reposição estoque terceiros & $\begin{array}{l}\text { [(Faturamento bruto mensal x premissa \% participação dos } \\
\text { fornecedores)] / premissa reposição estoque terceiros (Mark-up) }\end{array}$ \\
\hline Despesas com ST & Faturamento bruto mensal x premissa \% despesa com ST \\
\hline Despesa com DIFA & Faturamento bruto mensal $x$ premissa \% despesa com DIFA \\
\hline Perdas e outras despesas & Faturamento bruto mensal x premissa \% perdas e outras despesas \\
\hline Despesa com transporte & Reposição estoque CD X Percentual de despesa de transporte \\
\hline Despesa embalagens & Faturamento bruto mensal x percentual de despesa embalagens \\
\hline Royalties1 & Faturamento bruto mensal x percentual royalties 1 \\
\hline Royalties2 & Reposição estoque CD X royalties2 \\
\hline Fundo de publicidade & Faturamento bruto mensal x percentual do fundo de publicidade \\
\hline Desconto cartões & Faturamento bruto mensal x percentual de desconto de cartões \\
\hline Desconto diversos & Premissa descontos diversos \\
\hline Despesa financeira & Tarifas bancárias \\
\hline Simples Nacional & Faturamento bruto $\times$ Percentual do Simples Nacional \\
\hline
\end{tabular}

Definido os cálculos das variáveis usadas na análise da viabilidade econômico-financeira, foi projetado o fluxo de caixa dos 5 anos (Figura 2 representa o ano 1, sendo os cálculos análogos para os demais). A avaliação se iniciou em Outubro, tendo como base o momento de estudos implementação do negócio. 


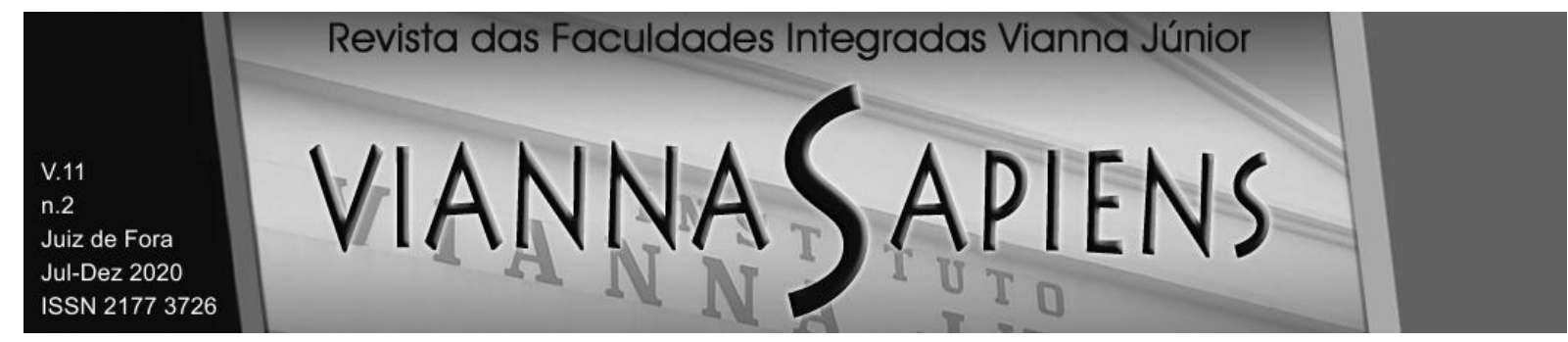

Figura 2 - Fluxo de caixa do primeiro ano.

\begin{tabular}{|c|c|c|c|c|c|c|c|c|c|c|c|c|}
\hline \multirow{2}{*}{ Fluxo de Caixa } & \multicolumn{12}{|c|}{ ANO 1} \\
\hline & Outubro & Novembro & Dezembro & Janeiro & Fevereiro & Março & Abril & Maio & Junho & Julho & Agosto & Setembro \\
\hline Taxa Franquia & R\$ 30.000 & & & & & & & & & & & \\
\hline Obras + mobiliário & \begin{tabular}{|l|l|} 
& 244.664 \\
\end{tabular} & & & & & & & & & & & \\
\hline Comunicação Visual & $\mathrm{R} \$ \mathbf{3 . 5 0 0}$ & & & & & & & & & & & \\
\hline Software LINX & $\mathrm{R} \$ \mathbf{7} 77$ & RS 777 & RS 777 & & & & & & & & & \\
\hline Projeto & $\mathrm{R} \$ 4.000$ & & & & & & & & & & & \\
\hline \multirow{2}{*}{ Equipamentos } & $R \$ 7.000$ & & & & & & & & & & & \\
\hline & & & & & & & & & & & & \\
\hline Taxa de transferência IMG? & $\mathrm{R} \$ 0$ & & & & & & & & & & & \\
\hline Taxa de transferência Shop & $\mathrm{R} \$ \mathbf{0}$ & & & & & & & & & & & \\
\hline \multirow[t]{2}{*}{ CDU - ponto comercial* } & $\mathrm{R} \$ \mathbf{3 0 . 0 0 0}$ & & & & & & & & & & & \\
\hline & & & & & & & & & & & & \\
\hline Total & R\$ 319.941 & RS 777 & RS 777 & $\mathrm{R} \$ \mathbf{0}$ & $\mathrm{R} \$ \mathbf{0}$ & $\mathrm{R} \$ \mathbf{0}$ & $\mathrm{R} \$ \mathbf{0}$ & $\mathrm{R} \$ \mathbf{0}$ & $\mathrm{R} \$ \mathbf{0}$ & $\mathrm{R} \$ 0$ & $\mathrm{R} \$ 0$ & $\mathrm{R} \$ 0$ \\
\hline \multicolumn{13}{|l|}{ CENÁRIO } \\
\hline Faturamento Projetado & R\$ 52.416 & $R \$ 60.480$ & R\$ 176.232 & R\$ 73.752 & R\$ 60.396 & R\$ 61.068 & R\$ 44.352 & $\mathrm{R} \$ 68.040$ & $\mathrm{R} \$ 72.240$ & R\$55.272 & R\$ 72.156 & $\mathrm{R} \$ 43.512$ \\
\hline Despesas + Custos Projetado & $\mathrm{R} \$ 50.953$ & $\mathrm{R} \$ 55.893$ & $\mathrm{R} \$ 138.914$ & $\mathrm{R} \$ 64.502$ & $R \$ 55.693$ & $R \$ 55.869$ & $\mathrm{R} \$ 46.517$ & $R \$ 60.535$ & $R \$ 63.485$ & $R \$ 52.629$ & $R \$ 63.204$ & $R \$ 45.877$ \\
\hline Lucro Líquido Mensal & $R \$ 1.463$ & $\mathrm{R} \$ 4.587$ & $R \$ 37.318$ & $\mathrm{R} \$ 9.250$ & $R \$ 4.703$ & $\mathrm{R} \$ 5.199$ & $-R \$ 2.165$ & $\mathrm{R} \$ 7.505$ & $R \$ 8.755$ & $\mathrm{R} \$ 2.643$ & $\mathrm{R} \$ 8.952$ & $-R \$ 2.365$ \\
\hline Margem / Faturamento & $2,79 \%$ & $7,58 \%$ & $21,18 \%$ & $12,54 \%$ & $7,79 \%$ & $8,51 \%$ & $-4,88 \%$ & $11,03 \%$ & $12,12 \%$ & $4,78 \%$ & $12,41 \%$ & $-5,44 \%$ \\
\hline Fluxo de Caixa 1 (c/ Instalação) & $-R \$ 318.478$ & $R \$ 3.810$ & R\$ 36.541 & R\$ 9.250 & $R \$ 4.703$ & $\mathrm{R} \$ 5.199$ & $-R \$ 2.165$ & R\$ 7.505 & $\mathrm{R} \$ 8.755$ & $R \$ 2.643$ & $R \$ 8.952$ & $-R \$ 2.365$ \\
\hline Acumulado 1 (Capital de Giro) & $-R \$ 318.478$ & $-\mathrm{R} \$ 314.668$ & $|-R \$ \$ 278.127|$ & $-R \$ 268.877$ & $-R \$ 264.174$ & $-R \$ 258.976$ & $-\mathrm{R} \$ 261.140$ & $-R \$ 253.636$ & $-R \$ 244.881$ & $-R \$ 242.238$ & $-R \$ 233.286$ & $-R \$ 235.651$ \\
\hline Acumulado 1 (Capital de Giro) - Sem Ponto Comercial & $-R \$ 288.478$ & - $-R \$ 284.668$ & $\begin{array}{c}\mid- \text {-R } 248.127 \\
\text { Fonte: }\end{array}$ & $\begin{array}{l}\text { - } \$ \text { S\$238.877 } \\
\text { : Autor }\end{array}$ & $\begin{array}{l}\mid-\mathrm{k} \$ 234.174 \\
\text { ria próp }\end{array}$ & $\begin{array}{l}\text {-R\$ } 228.976 \\
\text { oria. }\end{array}$ & $|-\mathrm{R} \$ 231.140|$ & $-R \$ 223.636$ & -R\$ 214.881 & -R\$212.238 & $|-R \$ 203.286|$ & -R\$205.651 \\
\hline
\end{tabular}

Para isso, foram considerados os custos de implementação da franquia (Tabela 2), em que o software LINX foi parcelado em 3 vezes. O Faturamento Projetado corresponde ao faturamento bruto, ou seja, o valor médio de faturamento (Tabela 5) multiplicado pelo fator de faturamento (Tabela 3).

As Despesas + Custos Projetados são obtidas pelo somatório de todos os custos variáveis, fixos e de mão de obra (Quadros 1, 2 e 3). O Lucro Líquido Mensal é calculado como a diferença entre o faturamento bruto (do mês) e o total de custos e despesas. A Margem/Faturamento representa a divisão o Lucro Líquido Mensal e Faturamento Projetado, expressado percentualmente.

O Fluxo de Caixa 1 (c/ Instalação) é a diferença entre o Lucro Líquido Mensal e os custos de implementação da franquia (mensal). O Acumulado 1 (Capital de Giro) é a soma entre o Acumulado do 1 (Capital de Giro) do mês anterior e o Fluxo de Caixa 1 (c/ Instalação) do mês analisado. Por fim, o Acumulado do 1 (Capital de Giro) - Sem Ponto Comercial desconsidera o valor de $\mathrm{R} \$ 30.000,00$ do $\underline{\mathrm{CDU} \text { - ponto }}$ comercial.

Com isso, notou-se que o payback do investimento seria obtido em $\underline{35 \text { meses }}$ (sem considerar os custos de CDU) e de 39 meses (considerando os custos de CDU). Esse é justamente o período que o acumulado das entradas supre as saídas 


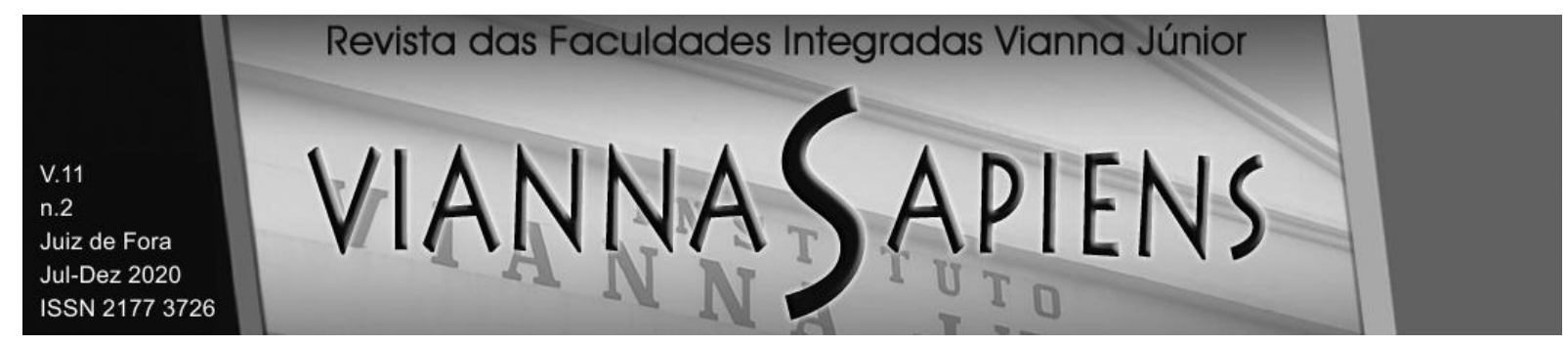

e os valores investidos para o desenvolvimento do negócio. Além disso, para a análise de fluxo de caixa, adotou-se como taxa de mínima atratividade (TMA) o valor de $1 \%$ ao mês, valor este julgado pelo investidor como atrativo à realização do investimento frente aos demais que tinha oportunidade operar.

O VPL calculado é de $R \$ 82.731,00$, em termos absolutos. O fato de ser superior a 0 demostra a viabilidade do investimento. Já a taxa interna de retorno (TIR) foi de 1,88\% ao mês e de $22,61 \%$ ao ano, sendo superior à TMA estipulada, reforçando o indicativo do VPL.

Para o ROIC, foram considerados outros grupos de conta para apuração dos resultados.

- Vendas: dado pela média de faturamento do ano (Tabela 5) multiplicado pelo fator peso de faturamento bruto do mês (Tabela 3). Representa o somatório dos faturamentos brutos mensais;

- Custo de Mercadoria Vendida (CMV): soma de reposição estoque CD, reposição de estoque de terceiros, despesa com ST, despesa com DIFA, com base nos valores da Tabela 9;

- Simples: resultado apurado do recolhimento de Simples projetado (Tabela 10);

- Royalties + Fundo de Publicidade (FP): royalties 1, royalties 2 e fundo de publicidade, com base nos valores da Tabela 9;

- Custo de Ocupação: descritos no Quadro 2;

- Despesas Pessoal: descritos no Quadro 1;

- Despesas Gerais: Perdas e outros despesas, despesas de transporte, despesa com embalagens, desconto cartões, descontos diversos, despesas financeiras, com base nos valores da Tabela 9;

- Lucro Líquido (LL): Vendas - (CMV) - (Simples) - (Royalties +FP) - (Custo de Ocupação) - (Despesas Pessoal) - (Despesas Gerais);

- Lucro Líquido/Receita Bruta (LL/RB): LL/Vendas. 


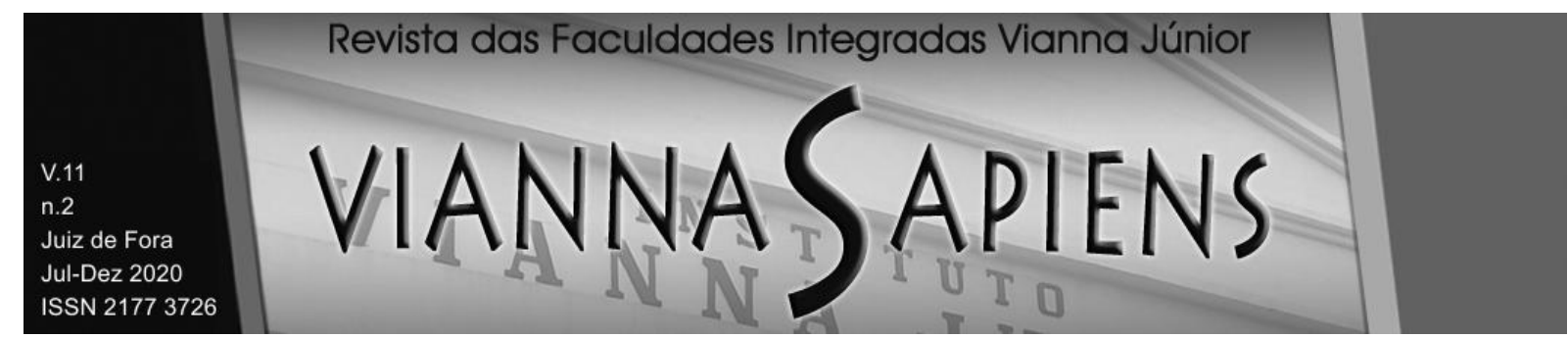

Dessa maneira, obtém-se a projeção da Figura 3 para os cinco anos em análise. Note que não foram consideradas as "Despesas Pessoal Variável".

Figura 3 - Primeira parte do cálculo de ROIC.

\begin{tabular}{|c|c|c|c|c|c|c|c|c|c|c|}
\hline & Vendas & CMV & Simples & Royaties + FP & $\begin{array}{l}\text { Custo de } \\
\text { Ocupação }\end{array}$ & $\begin{array}{c}\text { Despesas } \\
\text { Pessoal }\end{array}$ & $\begin{array}{c}\text { Despesas Pessoal } \\
\text { Variavel }\end{array}$ & $\begin{array}{c}\text { Despesas } \\
\text { Gerais }\end{array}$ & LL & LL/RB \\
\hline $1^{\circ}$ ano & $839.916,00$ & $239.203,24$ & $59.796,10$ & $138.643,79$ & $139.674,78$ & $139.350,35$ & - & $37.412,93$ & $85.834,81$ & $10,2 \%$ \\
\hline $2^{\circ}$ ano & $881.911,80$ & $251.163,24$ & $62.785,87$ & $145.575,89$ & $143.117,17$ & $141.561,21$ & - & $39.193,55$ & $98.514,86$ & $11,2 \%$ \\
\hline & & & & & & & & & & \\
\hline 30 ano & $926.007,39$ & $263.721,25$ & $71.807,88$ & $152.854,60$ & $146.793,35$ & $143.882,63$ & - & $41.063,20$ & $105.884,48$ & $11,4 \%$ \\
\hline $4^{\circ}$ ano & $972.307,76$ & $276.907,15$ & $75.398,23$ & $160.497,24$ & $150.719,92$ & $146.635,60$ & - & $43.026,34$ & $119.123,28$ & $12,3 \%$ \\
\hline 50 ano & 1.020 .923 .15 & 290.752 .35 & $79.168,10$ & 168.522 .01 & $154.945,50$ & 149.696 .62 & - & $45.087,63$ & 132.750 .94 & $13.0 \%$ \\
\hline
\end{tabular}

Fonte: Autoria própria.

A segunda parte do cálculo do ROIC leva em consideração os cálculos de rentabilidade por ano, estoque, contas a receber, contas a pagar, valor do ponto, obra civil, valor do mobiliário + equipamentos, kgiro, ativo e capital investido. São elas:

- Rentabilidade/ano: justamente o valor obtido no LL, calculado na Figura 3.

- Estoque: considera a relação $\mathrm{CMV} /(360 * 45)$, uma vez que 45 dias é o período médio de reposição de estoque, e 360 dias compõem 1 ano de operação.

- Contas a receber: considera a relação Vendas/(360*28), uma vez que 28 dias é o período médio de pagamento das compras a prazo, e 360 dias compõem 1 ano de operação.

- Contas a pagar: considera a relação (Vendas/Mark-up/360*42), sendo que o mark-up adotado de 2,65 (valor praticado pela franqueadora para a precificação dos produtos), 42 dias é o período médio de pagamento das contas devidas a franqueadora, e 360 dias compõem 1 ano de operação.

- Valor do ponto: considerou-se o valor de $\mathrm{R} \$ 30.000,00$.

- Obra civil: depreciação da obra civil considerando 5 anos de uso, valor inicial de investimento de $\mathrm{R} \$ 205.343,00$ e valor residual de $10 \%$ do valor inicial (Figuras 4 e 5); 


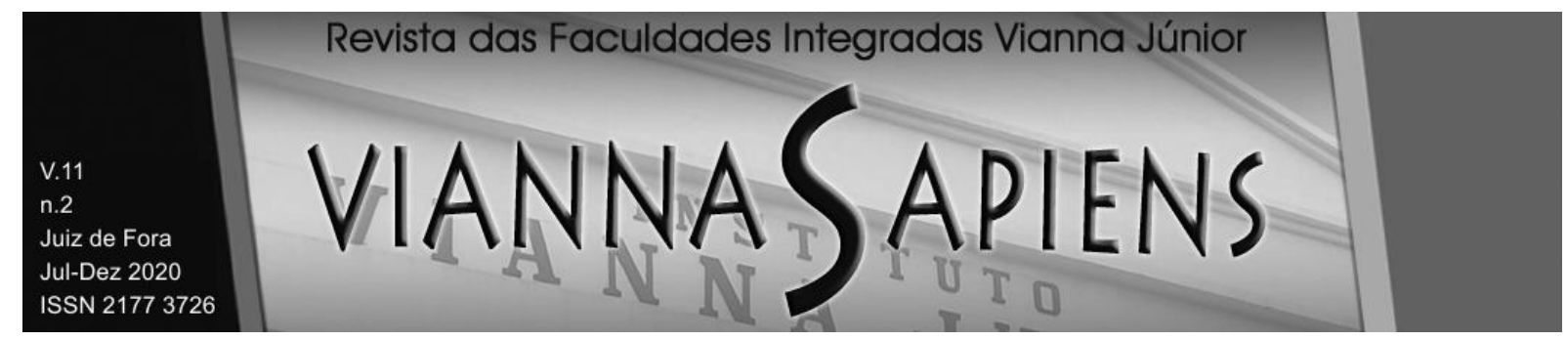

Figura 4 - Depreciação calculada para obra civil e mobiliário + equipamentos.

\begin{tabular}{|c|c|c|c|c|c|c|c|}
\hline & \multicolumn{7}{|c|}{ Depreciação } \\
\cline { 2 - 8 } & Anos & Valor Inicial & Ano 1 & Ano 2 & Ano 3 & Ano 4 & Ano 5 \\
\hline Obra Civil & 5 & $184.808,70$ & - & $41.068,60$ & $41.068,60$ & $41.068,60$ & $41.068,60$ \\
\hline Mobiliário + Equipamentos & 5 & $41.688,90$ & - & $9.264,60$ & $9.264,60$ & $9.264,60$ & $9.264,60$ \\
\hline \multicolumn{7}{|c|}{ Fonte: Autoria própria. }
\end{tabular}

O valor final (Figura 5), para cada ano, é justamente a diferença entre o valor de começo, deduzido o valor residual e o valor de depreciação (Figura 4).

Figura 5 - Depreciação calculada para obra civil e mobiliário + equipamentos.

\begin{tabular}{|c|c|c|c|c|}
\hline & \multicolumn{2}{|c|}{ Obra Civil } & \multicolumn{2}{c|}{ Mobiliário + Equipamentos } \\
\hline Ano & Começo & Final & Começo & Final \\
\hline Ano 1 & 184.809 & $184.808,70$ & 41.689 & 41.689 \\
\hline Ano 2 & 184.809 & $143.740,10$ & 41.689 & 32.425 \\
\hline Ano 3 & 143.740 & $102.671,50$ & 32.425 & 23.161 \\
\hline Ano 4 & 102.672 & $61.602,90$ & 23.161 & 13.896 \\
\hline Ano 5 & 61.603 & $20.534,30$ & 13.896 & 4.632 \\
\hline
\end{tabular}

Fonte: Autoria própria.

- Valor do mobiliário + equipamento: depreciação dos itens, considerando 5 anos de uso, valor inicial de investimento de $R \$ 46.321,00$ e valor residual de $10 \%$ do valor inicial do investimento (Figuras 4 e 5);

- Kgiro: considera (Estoque) + (Contas a Receber) - (Contas a Pagar);

- Ativo: considera a relação entre (Valor do ponto) + (Obra Civil) + (Valor do mobiliário + equipamento);

- Capital investido: considera a relação entre (kgiro) + (ativo);

Com todo esse conjunto, obtém-se o ROIC anual (Figura 6), que considera a relação entre (rentabilidade por ano)/(capital investido). 


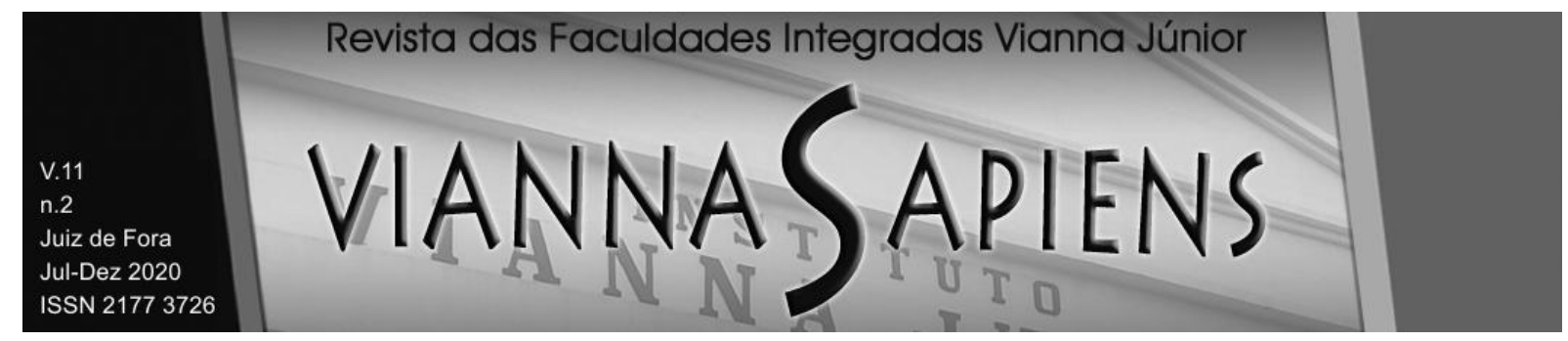

Figura 6 - Segunda parte do cálculo de ROIC.

\begin{tabular}{|c|c|c|c|c|c|c|c|c|c|c|}
\hline & \multicolumn{2}{|c|}{ Dias } & Mark Up & 2,65 & & & & & & \\
\hline & 45 & 28 & 42 & & & & & & & \\
\hline $\begin{array}{c}\text { Rentabilidade / } \\
\text { Ano }\end{array}$ & Estoque & $\begin{array}{l}\text { Contas a } \\
\text { Receber }\end{array}$ & $\begin{array}{c}\text { Contas a } \\
\text { pagar }\end{array}$ & $\begin{array}{l}\text { valor do } \\
\text { Ponto }\end{array}$ & Obra Civil & $\begin{array}{c}\text { Valor do } \\
\text { Mobiliario + } \\
\text { equipamento }\end{array}$ & Kgiro & Ativo & $\begin{array}{c}\text { Capital } \\
\text { Investido }\end{array}$ & Roic anual \\
\hline $85.834,81$ & $29.900,40$ & $65.326,80$ & $36.977,43$ & $30.000,00$ & $184.808,70$ & 41.689 & $58.249,77$ & $256.497,60$ & $314.747,37$ & $27,27 \%$ \\
\hline $98.514,86$ & $31.395,41$ & $68.593,14$ & $38.826,31$ & $30.000,00$ & $143.740,10$ & 32.425 & $61.162,24$ & $206.164,80$ & $267.327,04$ & $36,85 \%$ \\
\hline $105.884,48$ & $32.965,16$ & 72.022 .80 & 40.767 .62 & $30.000,00$ & $102.671,50$ & 23.161 & 64.220 .33 & $155.832,00$ & $220.052,33$ & $48,12 \%$ \\
\hline & & & & & & & & & & \\
\hline $119.123,28$ & $34.613,39$ & $75.623,94$ & $42.806,00$ & $30.000,00$ & $61.602,90$ & 13.896 & $67.431,33$ & $105.499,20$ & $172.930,53$ & $68,89 \%$ \\
\hline $132.750,94$ & $36.344,04$ & $79.405,13$ & $44.946,30$ & $30.000,00$ & $20.534,30$ & 4.632 & $70.802,88$ & $55.166,40$ & $125.969,28$ & $105,38 \%$ \\
\hline
\end{tabular}

Fonte: Autoria própria.

Note que o valor calculado de ROIC melhora com o passar dos anos considerados, refletindo maior Retorno Sobre o Capital Investido. Ou seja, maior eficiência da empresa franqueada em alocar o capital sob seu controle.

Trata-se de um resultado esperado, uma vez que com a maturidade assimilada pela empresa ao ampliar o horizonte de ação, possibilita-se a expansão das suas vendas. $E$, consequentemente, o aumento do seu faturamento $e$ consolidação do investimento. Assim, dados os resultados obtidos na pesquisa de mercado, nas demonstrações contábeis e nos índices econômico-financeiros, $\underline{0}$ empreendedor optou por investir na franquia.

\section{CONCLUSÃO}

A decisão de investir deve se basear na identificação de oportunidades, a partir de métodos objetivos de avaliação que indiquem o desempenho financeiro do negócio. Adotar tais critérios é um importante passo para a implementação de um empreendimento, que deve ter retorno financeiro.

Nesse sentido, a análise econômico-financeira se torna uma vantajosa ferramenta de análise. Especialmente em um contexto de crise e instabilidade 


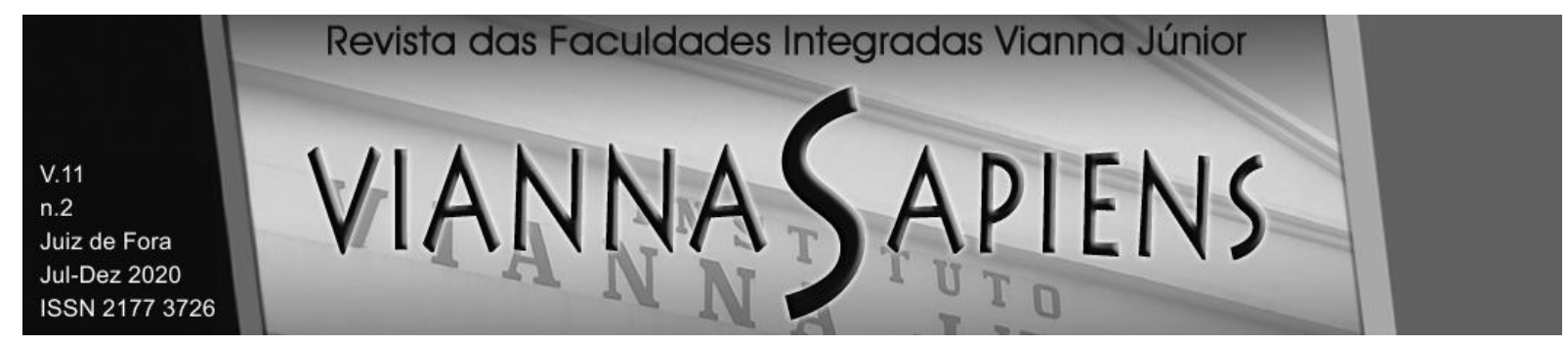

econômica, na qual esse investimento foi analisado, o qual foram demonstrados resultados positivos.

Com o estudo, foi possível obter o fluxo de caixa e determinar o payback em 35 meses e a Taxa Interna de Retorno em 1,88\% ao mês. Ao comparar a TIR com a TMA, tem-se que a TIR é maior que a TMA. Significa dizer que o investidor terá um retorno mensal de $0,88 \%$ mensal a mais. O resultado do Retorno sobre o Capital Investido (ROIC) é crescente ao longo dos cinco anos de avaliação, traduzindo-se em maior retorno sobre o capital investido.

Neste estudo, tanto o VPL, quanto as análises de TIR, payback e ROIC apontaram a positividade do retorno do investimento. Os resultados da pesquisa de mercado também revelam que o negócio se mostra uma oportunidade. Dessa forma, a implementação da franquia de artigos de presentes e decoração é viável e proporciona, a médio e longo prazo, retorno do capital investido.

O estudo limitou-se a construção de cenários, que não necessariamente correspondem com a realidade de atuação do negócio. Comparar a realidade de desempenho da empresa com o que foi projetado, no presente estudo, pode revelar quão assertiva foi a avaliação desenvolvida.

Portanto, pode-se concluir que a análise de viabilidade econômico-financeira influenciou a decisão de investimento na franquia de artigos de presentes e decoração. Tendo determinado prazos, taxas e valores que garantiram maior segurança ao investidor pelo fato de minimizar incertezas.

\section{REFERÊNCIAS}

ABF - ASSOCIAÇÃO BRASILEIRA DE FRANCHISING. 2019. Disponível em: < https://www.abf.com.br/Acesso em: 05 jun. 2020. 


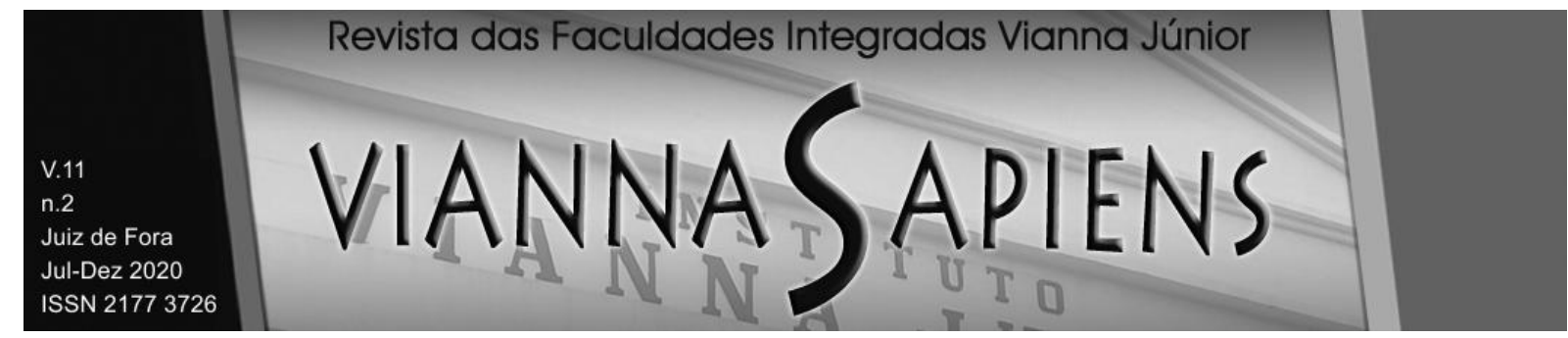

ABF - ASSOCIAÇÃO BRASILEIRA DE FRANCHISING. Desempenho do Franchising Brasileiro em 2018 e estudo sobre Microfranquias. 2018.

ABRASCE - ASSOCIAÇÃO BRASILEIRA DE SHOPPING CENTERS. 2019.

Disponível em: <https://abrasce.com.br/numeros/setor/>. Acesso em: 05 jun. 2020.

ALIANSCE SONAE. Boulevard shopping Vitória Da Conquista. 2019. Disponível em: http://www.alianscesonae.com.br/shopping/boulevard-shopping-vitoria-daconquista. Acesso em: 03 abr. 2020.

ASSAF NETO, A. Finanças corporativas e valor. 6. Ed. São Paulo: Atlas, 2012.

BAKKER, B.; SALGADO, J. "Quando a crise faz o empreendedor": desemprego e empreendedorismo no jornal O Estado de S. Paulo. In: Congresso Internacional Comunicação e Consumo, 2016, São Paulo.

BORDEAUX-RÊGO, R. Viabilidade econômico-financeira de projetos. 4. Ed. Rio de Janeiro: Editora FGV, 2013.

BOYD, H.; WESTFALL, R. Pesquisa mercadológica. Rio de Janeiro: FGV, 1978.

BROM, L. G.; BALIAN, J. E. A. Análise de investimentos e capital de giro: conceitos e aplicações. São Paulo: Saraíva, 2007.

CASAROTTO FILHO, N. Análise estratégica, estudo de viabilidade e plano de negócio. 5 ed. São Paulo: Atlas, 2014.

CASAROTTO FILHO, N.; KOPITTKE, B. H. Análise de Investimentos. São Paulo: Atlas, 2010.

COBRA, M. Administração mercadológica. São Paulo: Atlas, 1992. 


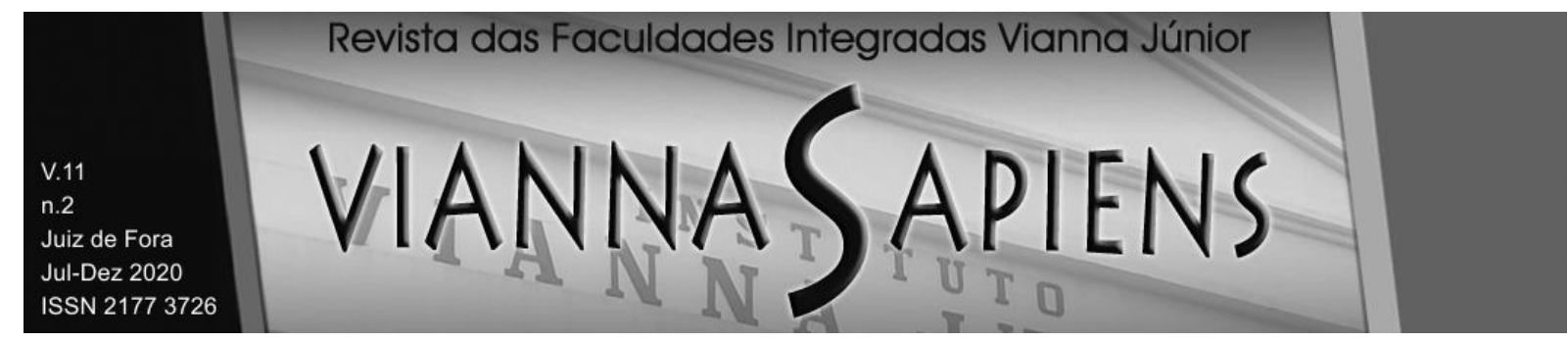

COPELAND, T.; KOLLER, T.; MURRIN, J. Avaliação de empresas - Valuation: calculando e gerenciando o valor das empresas. 3. Ed. São Paulo: Pearson Makron Books, 2002.

DAVIES, M. A.; LASSAR, W.; MANOLINS, C.; PRINCE, M.; WINSOR, R. D. A model of trust and compliance in franchise relationships. Journal of Business Venturing, v.26, n.3, p.321-340, 2011.

DHAVALE, D.G.; SARKIS, J. Stochastic internal rate of return on investments in sustainable assets generating carbon credits. Computers and Operations Research. 2017.

FERREIRA, R. G. Engenharia econômica e avaliação de projetos de investimento: critérios de avaliação: financiamentos e benefícios fiscais: análise de sensibilidade e risco. São Paulo: Atlas, 2009.

FONSECA, J. W. F. Elaboração e análise de projetos: a viabilidade econômicofinanceira. São Paulo: Atlas, 2012.

GHANTOUS, N.; JAOLIS, F. Conceptualizing franchisee-based brand equity: A framework of the sources and outcomes of the brand's added value for franchisees. International Business Research, v.6, n.2, p.112, 2013.

GIL, A. C. Métodos e técnicas de pesquisa social. 6. Ed. São Paulo: Atlas, 2010, $216 \mathrm{p}$.

GREENBLATT, J. The little book that still beats the market. John Wiley \& Sons, 2010. ISBN 0470926716.

HOJI, M. Administração financeira e orçamentária: matemática financeira e aplicada, estratégias financeiras, orçamento empresarial. 8. Ed. São Paulo: Atlas, 2010. 


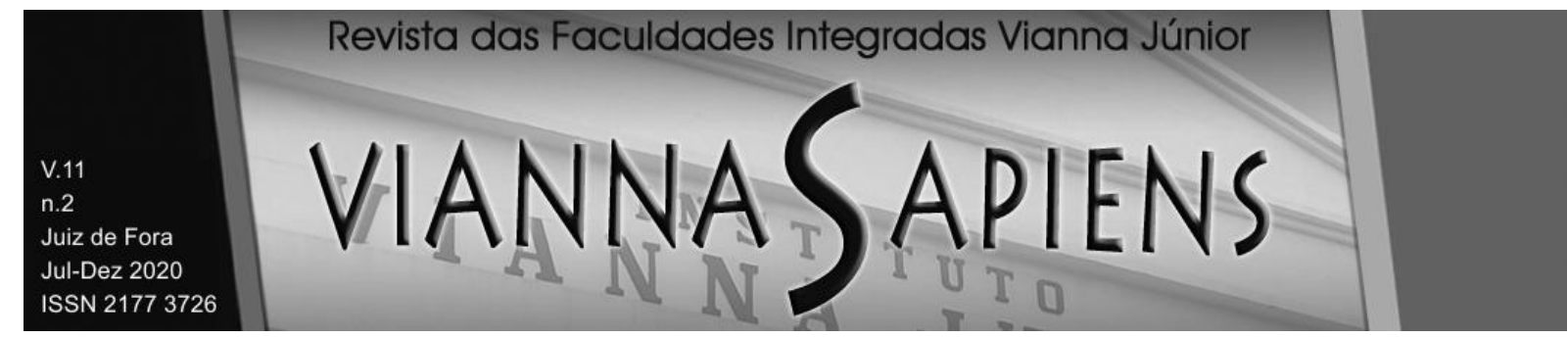

HOSS, O.; ZENCI, S. D.; ROJAS, L.; ALVARO, G. Investimento em projetos com base no planejamento estratégico: um estudo de caso em uma fábrica de carrinhos para supermercado. Revista de Gestão e Projetos, v.3, n.3, p. 181. 2012.

IBGE - INSTITUTO BRASILEIRO DE GEOGRAFIA E ESTATÍSTICA. Demografia das empresas: 2014. 2016.

KANTAMA, A.; NARATARUKSA, P.; HUNPINYO, P.; PRAPAINAINAR, C. Technoeconomic assessment of a heat-integrated process for hydrogenated renewable diesel production from palm fatty acid distillate. Biomass and Bioenergy. v.83, p. 448-459. 2015.

KASSAI, J. R. et al. Retorno de investimento: abordagem matemática e contábil do lucro empresarial. 2. Ed. São Paulo: Atlas, 2000.

LAKATOS, E. M.; MARCONI, M. A. Fundamentos de metodologia científica. 7. Ed. São Paulo: Atlas, 2010, 320 p.

LIZOTE, S. A. et al. Análise de Investimentos: um estudo aplicado em uma empresa do ramo alimentício. 2014. Trabalho apresentado ao XI Simpósio de Excelência em Gestão da Tecnologia, Universidade do Vale do Itajaí/RJ, 2014. Disponível em: https://www.aedb.br/seget/arquivos/artigos14/1220115.pdf. Acesso em: 20 abr. 2020.

MALHOTRA, N. K. Pesquisa de Marketing: uma orientação aplicada. 3. Ed. Porto Alegre: Bookman, 2001.

MARICATO, P. Franquias: Bares, restaurantes, lanchonetes, fast-foods e similares. 1. Ed. São Paulo: Senac, 2017, 333 p.

MASCARENHAS, M. P.; HYGINO, M. O.; SILVA, N. L. S. Empreendendo em franchising: uma análise das principais vantagens e desvantagens.

Empreendedorismo, Gestão e Negócios. v. 4, n. 4, p. 111-133. 2015. 


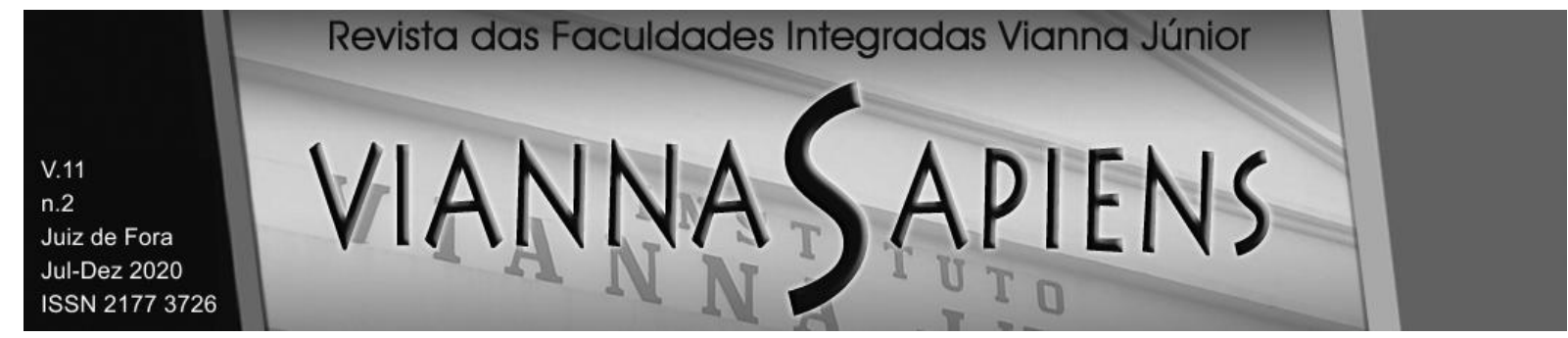

MATHEW, V.; THOMAS, S.; INJODEY, J. I. Direct and indirect effect of brand credibility, brand commitment and loyalty intentions on brand equity. Economic Review: Journal of Economics \& Business/Ekonomska Revija: Casopis za Ekonomiju i Biznis, v.10, n.2, 2012.

MAURO, P. C. Guia do franqueador: leitura obrigatória para quem quer comprar uma franquia. São Paulo: Nobel, 2007.

MELO, P. L..; BORINI, F. M.; CUNHA, J. A. C. Percepções de valor e elementos estruturantes das microfranquias. Revista de Administração Contemporânea, v.18, n.3, p.328-350, 2014.

NEVES, J. Avaliação e gestão da performance estratégica da empresa. 2. Ed. Lisboa: Texto Editora, 2011

NIJMEIJER, K. J.; FABBRICOTTI, I. N.; HUIJSMAN, R. Making franchising work: a framework based on a systematic review. International Journal of Management Reviews, v.16, n.1, p.62-83, 2014.

PILÃO, N. E. HUMMEL, Paulo Roberto Vampré. Matemática financeira e engenharia econômica: a teoria e a prática da análise de projetos de investimentos. São Paulo: Pioneira Thomson Learning, 2003.

POLIGNANO, L. A. C.; DRUMOND, F. B. O papel da pesquisa de mercado durante o desenvolvimento de produtos. In: CONGRESSO BRASILEIRO DE GESTÃO DE DESENVOLVIMENTO DE PRODUTOS, 3, 2001. Anais. UFSC, Florianópolis, SC, pp. 121-130, 2001.

RIBEIRO, A. et. al. Gestão estratégica do franchising: como construir redes de franquias de sucesso. 2. Ed. São Paulo: DVS Editora, 2013.

RICHARDSON, R. J. et al. Pesquisa social: métodos e técnicas. 3. ed. São Paulo: Atlas, 2010, $336 \mathrm{p}$. 


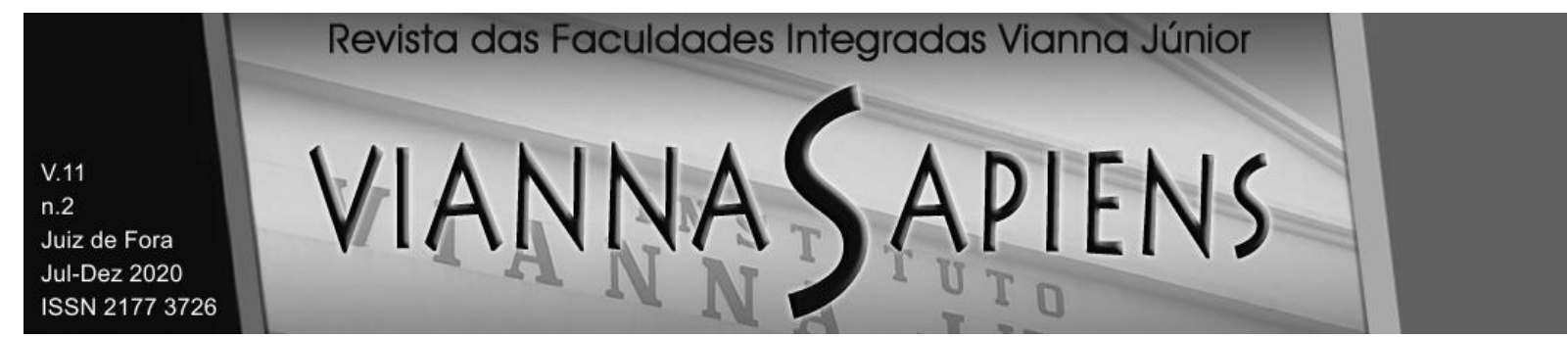

ROSS, S. A. et al. Princípios de Administração Financeira. 2. ed. São Paulo: Atlas, 2010.

SAMANEZ, C. P. Matemática Financeira: aplicações à análise de investimentos. 4. ed. São Paulo: Pearson. 2007.

SILVA, E. C. Contabilidade empresarial para gestão de negócios: guia de orientação fácil e objetivo para apoio e consulta de executivos. São Paulo: Atlas 2008, 234 p.

SIQUEIRA, I. Franchising: a revolução do seu negócio começa aqui. Recife: Do Autor, 2009.

SOUZA, A. B. Projetos de investimentos de capital: elaboração, análise, tomada de decisão. São Paulo: Atlas, 2003.

SPERTINO, F.; LEO, P.D.; COCINA, V. Economic analysis of investment in the rooftop photovoltaic systems: A long-term research in the two main markets.

Renewable and Sustainable Energy Reviews. v.28, 2013.

TEIXEIRA, N. A caracterização da estrutura financeira do sector das tecnologias de informação. 2008. Estudo apresentado no âmbito do Concurso de provas públicas para Professor Adjunto na ESCE na área científica de Finanças (edital no 682/2008), 2008.

VANSTRACEELE, P.; TOIT, T. Quantitative Value Investing in Europe: What works for achieving alpha, Kindle Edition, 2014.

VITÓRIA DA CONQUISTA (BA). Prefeitura. Economia. 2015. Disponível em: <https://www.pmvc.ba.gov.br/economia/>. Acesso em: 03 jun. 2020.

WARREN, C. S.; REEVE, J. M.; FESS, P. E. Contabilidade gerencial. 6. Ed. São Paulo: Pioneira Thomson Learning, 2001. 


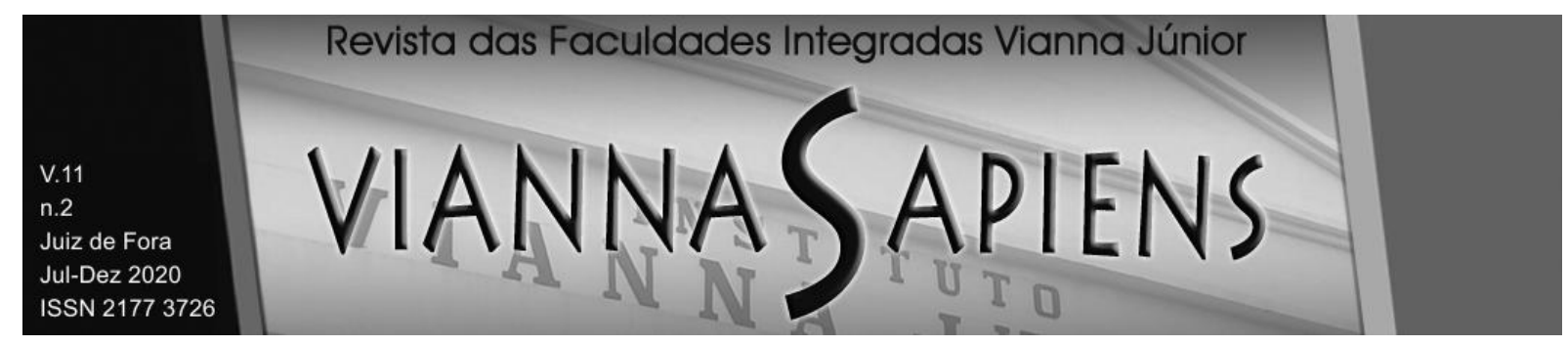

YIN, R. K. Estudo de caso: planejamento e métodos. Porto Alegre, Bookman, 2005.

ZAMBERLAN, L. Pesquisa de mercado. Ed. Unijuí, 2008.

ZANELLA, L. C. H. Metodologia de estudo e de pesquisa em administração / Liane Carly Hermes Zanella. - Florianópolis: Departamento de Ciências da Administração / UFSC; [Brasília]: CAPES: UAB, 2009.

Recebido em 15/04/2020

Publicado em 31/08/2020 